\title{
Population Exposure to Compound Droughts and Heatwaves in the Observations and ERA5 Reanalysis Data in the Gan River Basin, China
}

\author{
Yuqing Zhang ${ }^{1, *(\mathbb{D})}$, Guangxiong Mao ${ }^{1}$, Changchun Chen ${ }^{2}$, Liucheng Shen ${ }^{3}$ and Binyu Xiao ${ }^{1}$ \\ 1 School of Urban and Environmental Sciences, Huaiyin Normal University, Huai'an 223300, China; \\ gxmao123@126.com (G.M.); 51213901029@stu.ecnu.edu.cn (B.X.) \\ 2 School of Geographical Sciences, Nanjing University of Information Science \& Technology, \\ Nanjing 210044, China; 001309@nuist.edu.cn \\ 3 School of Environmental and Geographical Sciences, Shanghai Normal University, Shanghai 200234, China; \\ slc83328317@126.com \\ * Correspondence: 8201711019@hytc.edu.cn
}

Citation: Zhang, Y.; Mao, G.; Chen, C.; Shen, L.; Xiao, B. Population Exposure to Compound Droughts and Heatwaves in the Observations and ERA5 Reanalysis Data in the Gan River Basin, China. Land 2021, 10, 1021. https://doi.org/10.3390/ land10101021

Academic Editor: Giulio Iovine

Received: 21 August 2021

Accepted: 25 September 2021

Published: 28 September 2021

Publisher's Note: MDPI stays neutral with regard to jurisdictional claims in published maps and institutional affiliations.

Copyright: (c) 2021 by the authors. Licensee MDPI, Basel, Switzerland. This article is an open access article distributed under the terms and conditions of the Creative Commons Attribution (CC BY) license (https:/ / creativecommons.org/licenses/by/ $4.0 /)$.

\begin{abstract}
The frequency, duration, and magnitude of heatwaves and droughts are expected to increase in a warming climate, which can have profound impacts on the environment, society, and public health, and these may be severely affected specifically by compound droughts and heatwaves (CDHWs). On the basis of daily maximum temperature data and the one-month standardized precipitation evapotranspiration index (SPEI) from 1961 to 2018, the Gan River Basin (GRB) was taken as a case here to construct CDHW identification indicators and quantify the population exposure to CDHWs. We found that ERA5 reanalysis data performed well in overall simulating temperature, precipitation, one-month SPEI, heatwaves, and CDHWs in the GRB from 1961 to 2018. CDHWs during the period from 1997 to 2018 were slightly higher than that in 1961-1997. CDHWs were more likely to occur in the southern parts of the basin due to the relatively high values of drought-heatwave dependence indices. Atmospheric circulation analysis of the 2003 CDHW in the GRB showed a relatively long-lasting anomalous high pressure and anticyclonic circulation system, accompanied by the positive convective inhibition and surface net solar radiation anomalies. These circulating background fields eventually led to the exceptional 2003 CDHW occurrence in the GRB. The population exposure to CDHWs basically increased, especially for the moderate CDHWs in ERA5. The change in total exposure was mainly due to climate change. Compared with the period from 1989 to 1998, the contributions of the population change effect in 2009-2018 gradually increased with the increase in the CDHW magnitude both in the observations and ERA5 reanalysis data.
\end{abstract}

Keywords: compound droughts and heatwaves; population exposure; ERA5; Gan River Basin; China

\section{Introduction}

A combination of climate extremes (e.g., low precipitation and high temperatures) have received much attention due to their disproportionate and amplified impacts on the ecosystems and societies across the world [1-8]. For example, the 2003 European heatwaves, 2010 Russian heatwaves, 2013 Chinese heatwaves, and 2018 German heatwaves were all accompanied by severe droughts, which caused a large number of casualties, crop failure, wildfires, and infrastructural damages [9-12]. The special report by the Intergovernmental Panel on Climate Change (IPCC) remarked that a combination of multiple climate events can be termed as a compound event [13], and recommended three general definitions to describe it as such: (a) two or more extreme events occurring simultaneously or successively, (b) a combination of multiple extremes with underlying conditions that amplify the impact of the individual extremes, and (c) a combination of multiple events that are not extremes at their individual level but lead to an extreme 
event or impact when they combined. Subsequently, compound events were further divided into four categories based on the weather/climate drivers and hazards/risks [2,5]: (a) preconditioned events due to one or more hazards under particular pre-existing conditions (e.g., floods may arise from a combination of extreme precipitation and "preconditioned" saturated soils), (b) multivariate events occurring simultaneously in the same region (e.g., concurrent droughts and heatwaves), (c) temporally compounding events, for example, a succession of hazards (the same or different events) that affect a given region (e.g., a flood followed by heatwaves), and (d) spatially compounding events occurring in connected areas that are affected by the same or different hazards within a limited time window (e.g., synchronous crop failures due to heatwaves and/or droughts). According to the complexity of compound events, their eventual impacts in some cases inevitably fall into more than one category due to the soft boundaries (i.e., flexibility of boundaries) within the typology of compound events.

Compound droughts and heatwaves (CDHWs) are common natural disaster phenomena considered compound events, and they have significant impacts on the environment, social economy, and human health. High temperature lasts for a long time and is accompanied by a shortage of precipitation, which can induce the CDHW occurrence due to the negative correlation between precipitation and temperature during summer in some regions [3]. Droughts and heatwaves can intensify and expand via land-atmosphere feedbacks [14]. Exploring the possible dependence of drought-heatwave events in different regions is helpful to understand which areas have a high probability of CDHWs [3]. Recently, the percentile threshold method was used to investigate CDHWs based on the precipitation and temperature data [15-17]. The drought index (e.g., standardized precipitation index and standardized precipitation evapotranspiration index) combined with the daily maximum temperature data has been used to further identify CDHWs and for an in-depth understanding of CDHWs [3,18-21]. Although there have been many studies on the indices of droughts or heatwaves [22-26], the CDHW indices are few because the definitions and dimensions of droughts and heatwaves are different. For the construction of the CDHW index, the drought index and the heatwave index can be normalized separately and then multiplied during the specific period [19]. Thus, exploring the changes in CDHWs based on the severity (CDHW magnitude index) may prove to be useful for understanding CDHW characteristics.

Reanalysis products are important datasets for estimating the hydroclimatic characteristics, especially for the areas with sparse observation stations. ERA5 is the new fifth-generation reanalysis dataset released by the European Centre for Medium Range Weather Forecasts (ECMWF), which contains a large number of hydroclimatic variables with a high spatio-temporal resolution. This dataset was established via the $4 \mathrm{D}$-Var assimilation method, which combines model data with observations from across the world into a global dataset. As an upgraded version of ERA-Interim, ERA5 has a rigorous physical process foundation and high quality with high spatio-temporal resolution for a long period, and has been widely applied in hydrometeorological investigations and evaluations [27-33]. The ERA5 reanalysis dataset is divided into two parts by time span: 1950-1978 (preliminary back extension) and from 1979 onwards (final release plus timely updates). At present, there is a lack of evaluation of ERA5 in CDHWs, especially in humid subtropical basins. Hence, evaluating the ability of ERA5 data for identifying CDHWs can allow scientific measures to be taken to manage and handle compound events in a timely manner.

Heatwaves can cause heat stroke and can affect the elderly, infants, and persons with pre-existing cardiovascular and respiratory conditions, and may further increase morbidity and mortality rates [34-37]. If heatwaves occur during the drought period, then their destructive power is greater than that of individual heatwaves on natural environments, society, economy, and human health. For instance, strong heatwaves coincided with severe droughts in eastern China during the summer of 2013, and caused severe damage to the local environment, society, economy, and human health $[11,38]$. The damage was particularly severe in both eastern and southern China, which are densely populated areas [11,39]. 
Scenario population data (e.g., shared socioeconomic pathways) have been examined to explore the characteristics of population exposure to climate extremes [40], such as extreme precipitation [41], heatwaves [36,42], and droughts [43,44]. Yet, research on the exposure of the population to hydroclimatic extremes using long-term population observation data is still relatively rare, especially for CDHWs. The population exposure to climate extremes depends not only on climate change, but also on changes in the sizes and distributions of human populations [42]. Analysis of the relative contributions of different incorporated parameters (e.g., climate factor, population number, and the nonlinearity of both factors) to changes in overall exposure can provide important information regarding vulnerability to CDHW-related health problems.

In this study, we used the Gan River Basin (GRB) as a case to explore the characteristics of population exposure to CDHWs. The primary goals of this study included (1) evaluating the accuracy of ERA5 data in monitoring precipitation, temperature, heatwaves, droughts, and CDHWs; (2) exploring the characteristics of CDHWs and drought-heatwave dependence; (3) investigating population exposure to CDHWs, especially compound events in different grades based on CDHW magnitudes; and (4) quantifying the contributions of CDHW (climate change effect), population number (population change effect), and the nonlinearity of the previous two factors (joint change effect) to the overall exposure changes. The evaluation of population exposure to CDHWs was expected to provide a workable basis for mitigating potential losses due to CDHWs in regions that share similar climatic and socio-economic characteristics with the GRB.

\section{Materials and Methods}

\subsection{Study Area}

The GRB is located within the central and southern parts of the Poyang lake basin (the largest freshwater lake in China), with an area of $80,948 \mathrm{~km}^{2}$ (approximately the size of South Carolina in the U.S.), and is observed by the Waizhou hydrological station (outlet of the GRB). The GRB represents the largest sub-basin both in area (51\%) and runoff (50\%) of the Poyang lake basin. Mountains and foothills are most located in the southern parts of the GRB and flat plain areas exist in the northern parts of the GRB. The GRB belongs to a subtropical humid monsoon climate zone and has average annual precipitation of $1600.1 \mathrm{~mm}$ and an annual mean temperature of $18.2^{\circ} \mathrm{C}$ [45]. The GRB mainly covers six prefecture-level cities: Nanchang, Yichun, Xinyu, Pingxiang, Ji'an, and Ganzhou. The total population of the GRB was approximately 27.87 million at the end of 2018. The GRB is often affected by droughts and heatwaves in the summer months, and the number of these two events is likely to increase in the future [46], which may have a great impact on the natural environment, society, and economy.

\subsection{Data}

Meteorological observations included daily precipitation, maximum temperature $\left(T_{\max }\right)$, and mean temperature ( $\left.T_{\text {mean }}\right)$ from 1961 to 2018. These observations were provided by the National Meteorological Information Centre of the China Meteorological Administration (http:/ / data.cma.cn/, accessed on 18 September 2021) and were subjected to quality control and homogeneity assessments before release. To ensure the integrity and continuity of the data series, a meteorological station was removed from the study if the proportion of the missing values was more than $0.15 \%$ (i.e., 31 days) of the daily values during 1961-2018. The missing value was interpolated using the average value of 10 neighboring stations on the same day. We ultimately selected 47 meteorological stations (Figure 1) across the GRB spanning 1961-2018. 


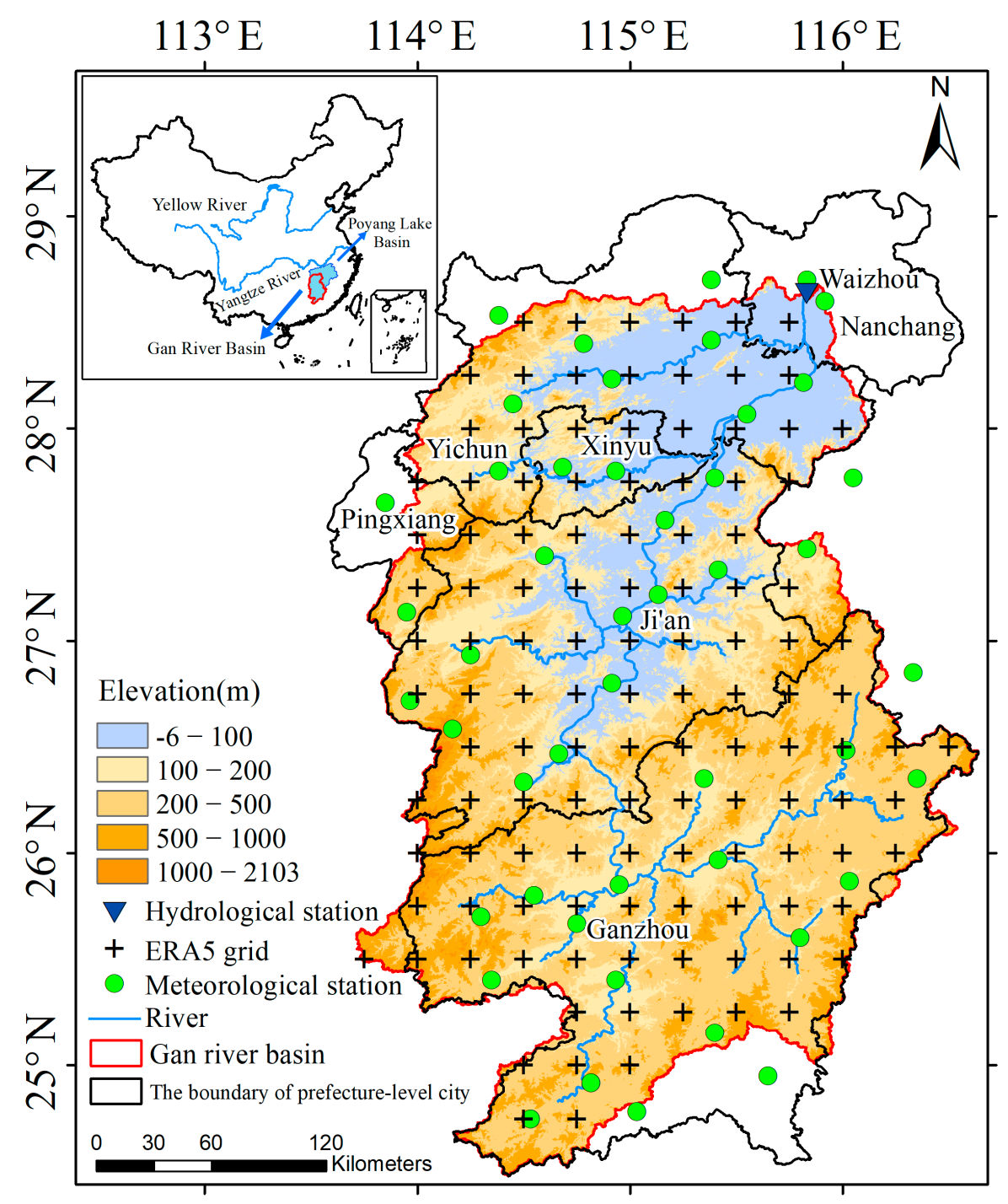

Figure 1. Location of 47 meteorological stations, one hydrological station (outlet), and 121 ERA5 grids in the GRB.

The ERA5 reanalysis datasets with $0.25^{\circ}$ spatial resolution and hourly temporal resolution were obtained from the fifth-generation ECMWF atmospheric reanalysis of the global climate [47]. In order to be consistent with the year length of the observation data, we selected the precipitation and temperature data from 1961 to 2018 in ERA5 for evaluation. The number of ERA5 grids in the GRB is 121 grids (Figure 1). Because the ERA5 are hourly datasets, we summed the $24 \mathrm{~h}$ of precipitation in a certain day as the daily precipitation, and the monthly and annual precipitation could be calculated via a similar approach. The maximum value of $24 \mathrm{~h}$ for a temperature value in a given day was regarded as the $T_{\max }$ of that day, and the mean value of $24 \mathrm{~h}$ for a temperature value in a given day was regarded as the $\mathrm{T}_{\text {mean }}$ of that day.

We used ERA5 atmospheric reanalysis data including the $500 \mathrm{hPa}$ geopotential height, water vapor flux, convective inhibition, total cloud cover, and surface net solar radiation to explore mechanisms of the $2003 \mathrm{CDHW}$. These atmospheric reanalysis data in ERA5 during $1961-2018$ were also of $0.25^{\circ}$ spatial resolution and hourly temporal resolution.

The GRB resident population data were obtained from China's economic and social big data research platform (http: / / data.cnki.net/, accessed on 18 September 2021). The GRB consists of six prefecture-level cities (i.e., Nanchang, Yichun, Xinyu, Pingxiang, Ji'an, and Ganzhou) in Jiangxi province. Because population statistics are generally based on administrative regions, the administrative boundaries of the prefecture-level cities have 
been relatively stable in the past three decades, so we used the total population of each prefecture-level city as the statistical unit in the GRB from 1988 to 2018 for analysis.

\subsection{Evaluation Metrics}

To quantitatively compare the ERA5 reanalysis data against ground observations, five statistical indices including mean bias (Bias), relative bias $(R B)$, the correlation coefficient $(r)$, root mean square error (RMSE), and the distance between the indices of simulation and observation (DISO) $[48,49]$ were employed in this study. These evaluation metrics are expressed as follows:

$$
\begin{gathered}
\text { Bias }=\frac{1}{n} \sum_{i=1}^{n}\left(S_{i}-O_{i}\right) \\
R B=\frac{\sum_{i=1}^{n}\left(S_{i}-O_{i}\right)}{\sum_{i=1}^{n} O_{i}} \times 100 \% \\
r=\frac{\sum_{i=1}^{n}\left(O_{i}-\bar{O}\right) \cdot\left(S_{i}-\bar{S}\right)}{\sqrt{\sum_{i=1}^{n}\left(O_{i}-\bar{O}\right)^{2} \cdot \sqrt{\sum_{i=1}^{n}\left(S_{i}-\bar{S}\right)^{2}}}} \\
R M S E=\sqrt{\frac{1}{n} \sum_{i=1}^{n}\left(S_{i}-O_{i}\right)^{2}} \\
D I S O=\sqrt{(r-1)^{2}+N B^{2}+N R M S E^{2}}
\end{gathered}
$$

where $S_{i}$ and $O_{i}$ are the simulations (i.e., ERA5) and observations at each time step $i$ (e.g., daily and monthly temporal scales), $n$ is the number of time steps, $\bar{S}$ and $\bar{O}$ are the mean values of simulations and observations, $N B$ is Bias divided by the $\bar{O}$ value, and NRMSE is RMSE divided by the $\bar{O}$ value. The closer Bias, $R B$, and RMSE are to zero, the closer the simulations are to the observations. DISO is a comprehensive index that combines $r$, Bias, and RMSE according to the distance between the simulations and observations in a three-dimensional space coordinate system [49]. When the DISO value is equal to zero, the simulated value is equivalent to the observed value. It is worth noting that DISO is invalid when $\bar{O}$ equals zero [48], and this is because a small difference in $\bar{O}$ can cause a large difference in DISO when $\bar{O}$ is very close to zero.

\subsection{Drought Definition}

In this study, we defined "meteorological drought" as an event that leads to a 1-month SPEI $<-1$ (approximately the 18th percentile of SPEI values in the GRB), which is similar to the meteorological drought criteria defined in previous studies $[4,6,21]$. The calculation of SPEI is mainly based on monthly precipitation and $\mathrm{T}_{\text {mean }}$, and a detailed calculation of the SPEI can be found in previous studies [6,26]. In this study, the Thornthwaite method was used to calculate potential evapotranspiration (PET) because this method is feasible and effective based on relatively few meteorological variables. The Thornthwaite method has already been widely applied in SPEI calculations $[6,21,26,50,51]$.

We defined the drought magnitude as the absolute value of the difference between the drought indicator $(D I$, i.e., SPEI $<-1$ ) and the threshold (SPEI $=-1$ ) during a specific month (denoted as $|\Delta D I|$ ). In order to facilitate the construction of the subsequent compound event magnitude index, we respectively normalized the drought and heatwave magnitude indices. The normalization formula is calculated as follows:

$$
R_{i}=0.9 \times \frac{x_{i}-x_{\min }}{x_{\max }-x_{\min }}+0.1
$$

where $R_{i}$ and $x_{i}$ are the $i$ th normalized result and input data, and $x_{\min }$ and $x_{\max }$ are the minimum and maximum values of the input data series.

The normalization formula (Equation (6)) was used to normalize $|\Delta D I|$ to [0.1 1] (denoted as $R|\Delta D I|$ ). $R|\Delta D I|$ was defined as the final drought magnitude index (DMI) in 
this study. If the minimum $R|\Delta D I|$ is equal to 0 , the drought event with a small magnitude may be classified as 0 , which is inappropriately regarded as a drought-free phenomenon [6].

\subsection{Heatwave Definition}

A hot event is generally defined as a $T_{\max }$ in more than the 90th or 95th percentile during the specific period $[21,22,36]$. Considering the climate characteristics of the GRB, a hot event (hot day) here was defined by the daily $\mathrm{T}_{\max }>90$ th percentile of the local daily climatology from 1961 to 2018 . A heatwave event (one event) was identified when a hot event lasted for at least three consecutive days at a given station. The intensity of a hot event (day) was defined as the temperature deviations exceeding the 90th percentile thresholds (denoted as $\left.|\Delta T|=\left|T_{\max }-T_{\max 90 t h}\right|\right)$. Then, the $|\Delta T|$ was also normalized with [0.1 1] via Equation (6) (denoted as $R|\Delta T|$ ). The heatwave magnitude index (HWMI) can be written as follows:

$$
H W M I=\sum_{i=1}^{n} R\left|\Delta T_{i}\right|
$$

where $R\left|\Delta T_{i}\right|$ denotes the magnitude of $i$ th heatwave day and $n \geq 3$.

\subsection{Compound Drought and Heatwave Definition}

CDHW was defined in this study as "simultaneous", meeting the definition of a meteorological drought and heatwave for the same month at a given station. When one or more heatwaves occurred during a meteorological drought period (i.e., one month), we counted it as a compound event. Heatwaves occurring across monthly boundaries were allocated to the month in which they started [3]. We established the compound drought and heatwave magnitude index (CDHMI), which can be compared across regions and over time by incorporating both the magnitude (intensity per unit time) and the duration of the compound events. For a given station, CDHMI can be calculated as follows:

$$
C D H M I=\left(\sum_{i=1}^{D_{n}} R\left|\Delta T_{i}\right|\right) \cdot R\left|\Delta D I_{n}\right|
$$

where $D_{n}$ is the number of heatwave days for the $n$th month. $\sum_{i=1}^{D_{n}} R\left|\Delta T_{i}\right|$ is the HWMI for the $n$th month and $R\left|\Delta D I_{n}\right|$ is the DMI for the $n$th month. The CDHMI is computed for a single specific month (e.g., June) and the annual CDHMI reported here is the sum of monthly CDHMI values during the specific year.

\subsection{D-H Dependence Index}

The drought-heatwave (D-H) dependence index reflects the degree of dependence between droughts and heatwaves [3]. This index was constructed as the ratio of monthly heatwave frequency (occurrence number), duration (days), and magnitude for the drought months to the corresponding statistics for all months in the record, respectively denoted as $D H_{F}, D H_{D}$, and $D H_{M}$ :

$$
\begin{aligned}
D H_{F} & =\frac{H F_{D} / D M}{H F / T M} \\
D H_{D} & =\frac{H D_{D} / D M}{H D / T M} \\
D H_{M} & =\frac{H M_{D} / D M}{H M / T M}
\end{aligned}
$$

where $H F_{D}(H F), H D_{D}(H D)$, and $H M_{D}(H M)$ respectively denote the heatwave frequency, duration, and magnitude during drought (all) months in a specific period (e.g., 1961-2018); $D M$ and $T M$ represent the number of drought months and all months in the record, re- 
spectively. The larger the value of the D-H dependence index, the stronger the dependence between droughts and heatwaves.

\subsection{Contribution Population Exposure to CDHWs}

The population exposure index is measured by the number of citizens exposed to the relevant indicators (i.e., CDHW frequency and CDHMI) of the compound event, that is, the annual indices of compound events multiplied by the corresponding annual number of people exposed to that outcome [36,42]. Therefore, the measurement units of population exposure to CDHW frequency and CDHMI are person-events and personCDHMI, respectively. The population data extend from 1988 to 2018, so the GRB population exposure was measured for 1988-2018 as well.

We applied the rate of change to analyze the changes in magnitude for exposure:

$$
\text { ERate }=\frac{E_{j}-E_{i}}{E_{i}} \times 100 \%
$$

where ERate denotes the change rate of the exposure. $E_{i}$ and $E_{j}$ represent the exposure in the period $i$ and $j$, respectively.

According to the relative contribution analysis method [41,42], we assessed the contributions of the compound event, population number, and the nonlinearity of the previous two factors (joint change effect) to the overall exposure changes. The decomposition for the exposure change can be expressed as:

$$
\begin{gathered}
\Delta E=C_{j} \times P_{j}-C_{i} \times P_{i} \\
=\left(C_{i}+\Delta C\right) \times\left(P_{i}+\Delta P\right)-C_{i} \times P_{i} \\
=C_{i} \times P_{i}+\Delta C \times P_{i}+C_{i} \times \Delta P+\Delta C \times \Delta P-C_{i} \times P_{i} \\
=\Delta C \times P_{i}+C_{i} \times \Delta P+\Delta C \times \Delta P
\end{gathered}
$$

where $\Delta E$ denotes the change in exposure. $C_{i}$ and $P_{i}$ represent the compound event index (i.e., $\mathrm{CDHW}$ frequency or CDHMI) and population number in the period $i$, respectively. $C_{j}$ and $P_{j}$ represent the compound event index and population number in the period $j$, respectively. $\Delta C$ and $\Delta P$ denote the changes in compound event index and population number from period $i$ to period $j$, respectively. The final form of Equation (13) consists of three terms that represent the different contributions of these factors to the overall exposure changes. The first term, $\Delta C \times P_{i}$, denotes the contribution from the compound event index to the overall exposure changes under the condition that the population is unchanged (i.e., climate change effect). The second term, $C_{i} \times \Delta P$, represents the contribution from the population change (i.e., population change effect). The third term, $\Delta C \times \Delta P$, is a nonlinear term (i.e., joint change effect or interaction effect) associated with changes in both the compound event index and population number of the exposure.

The rate of contribution of each factor can be written as follows:

$$
\begin{aligned}
& C R_{C}=\frac{\left|\Delta C \times P_{i}\right|}{\left|\Delta C \times P_{i}\right|+\left|C_{i} \times \Delta P\right|+|\Delta C \times \Delta P|} \times 100 \% \\
& C R_{P}=\frac{\left|C_{i} \times \Delta P\right|}{\left|\Delta C \times P_{i}\right|+\left|C_{i} \times \Delta P\right|+|\Delta C \times \Delta P|} \times 100 \% \\
& C R_{J}=\frac{|\Delta C \times \Delta P|}{\left|\Delta C \times P_{i}\right|+\left|C_{i} \times \Delta P\right|+|\Delta C \times \Delta P|} \times 100 \%
\end{aligned}
$$

where $C R_{C}, C R_{P}$, and $C R_{J}$ denote the contributions of climate change effect, population change effect, and joint change effect, respectively. 


\section{Results}

\subsection{Individual Droughts and Heatwaves}

Before evaluating ERA5 to simulate CDHWs, we need to evaluate precipitation and temperature in ERA5. On the daily scale, the precipitation in ERA5 can reasonably reflect the characteristics of the observed values, with high $r(0.767)$ and low $R B(14.18 \%$, representing precipitation overestimation by $14.18 \%)$, Bias $(0.63 \mathrm{~mm}), R M S E(5.28 \mathrm{~mm})$, and DISO (1.223) values (Figure 2a). The simulation effect of ERA5 precipitation on the monthly scale was obviously improved compared to that on the daily scale, with $r$ as high as 0.956 and DISO as low as 0.329 (Figure $2 \mathrm{~b}$ ).
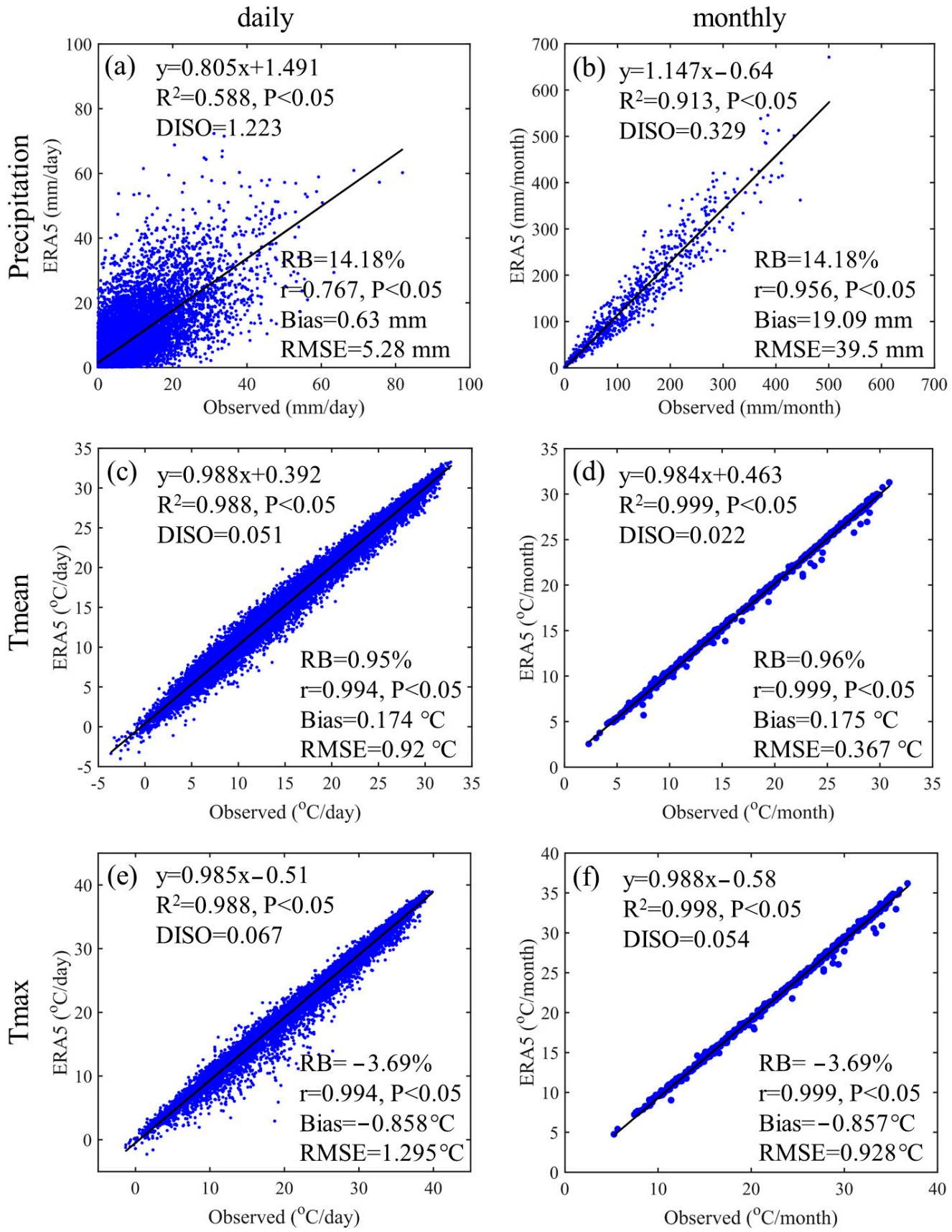

Figure 2. Scatter plots of $(\mathbf{a}, \mathbf{b})$ precipitation, $(\mathbf{c}, \mathbf{d}) \mathrm{T}_{\text {mean, }}$ and $(\mathbf{e}, \mathbf{f}) \mathrm{T}_{\max }$ from the ERA5 against the observations averaged GRB from 1961 to 2018. The left and right columns represent the daily and monthly values, respectively. 
The daily-scale simulation effect of ERA5 $\mathrm{T}_{\text {mean }}$ performed better than that of the precipitation (Figure $2 \mathrm{c}$ ), with higher $r(0.994)$ and lower $R B(0.95 \%)$, Bias $\left(0.174{ }^{\circ} \mathrm{C}\right), R M S E$ $\left(0.92^{\circ} \mathrm{C}\right)$, and DISO $(0.051)$. The simulation effect of the monthly-scale $\mathrm{T}_{\text {mean }}$ was slightly better than that of the daily scale (Figure 2d). The simulation effects of ERA5 $\mathrm{T}_{\max }$ on the daily (Figure 2e) and monthly (Figure 2f) scales were similar to those of the $\mathrm{T}_{\text {mean }}$, but were slightly underestimated. In general, ERA5 performed well in precipitation and temperature in the GRB.

The one-month SPEI value fluctuated greatly above and below the zero line (Figure 3a), which reflects the characteristics of the dry/wet conditions at short timescales. According to the statistical evaluation results of $r(0.927)$, Bias (0), RB (0.63\%), and RMSE (0.333), ERA5 effectively represented the characteristics of the one-month SPEI in the GRB. As shown in Figure 3b, a value of $r$ as high as 0.865 indicates that ERA5 better reflected the annual variations of DMI. Bias and $R B$ were as low as -0.039 and $-5.37 \%$, respectively, indicating that ERA5 overall slightly underestimated the DMI. The DMI simulation errors of ERA5 in 1963, 1971, and 1972 were relatively high. Overall, the DMI simulation performance of ERA5 during 1997-2018 was better than that of 1961-1997. The average value of the DMI in 1997-2018 was slightly higher than that in 1961-1997 both in the observations and ERA5, which indicates that the severity of drought had increased in the GRB.
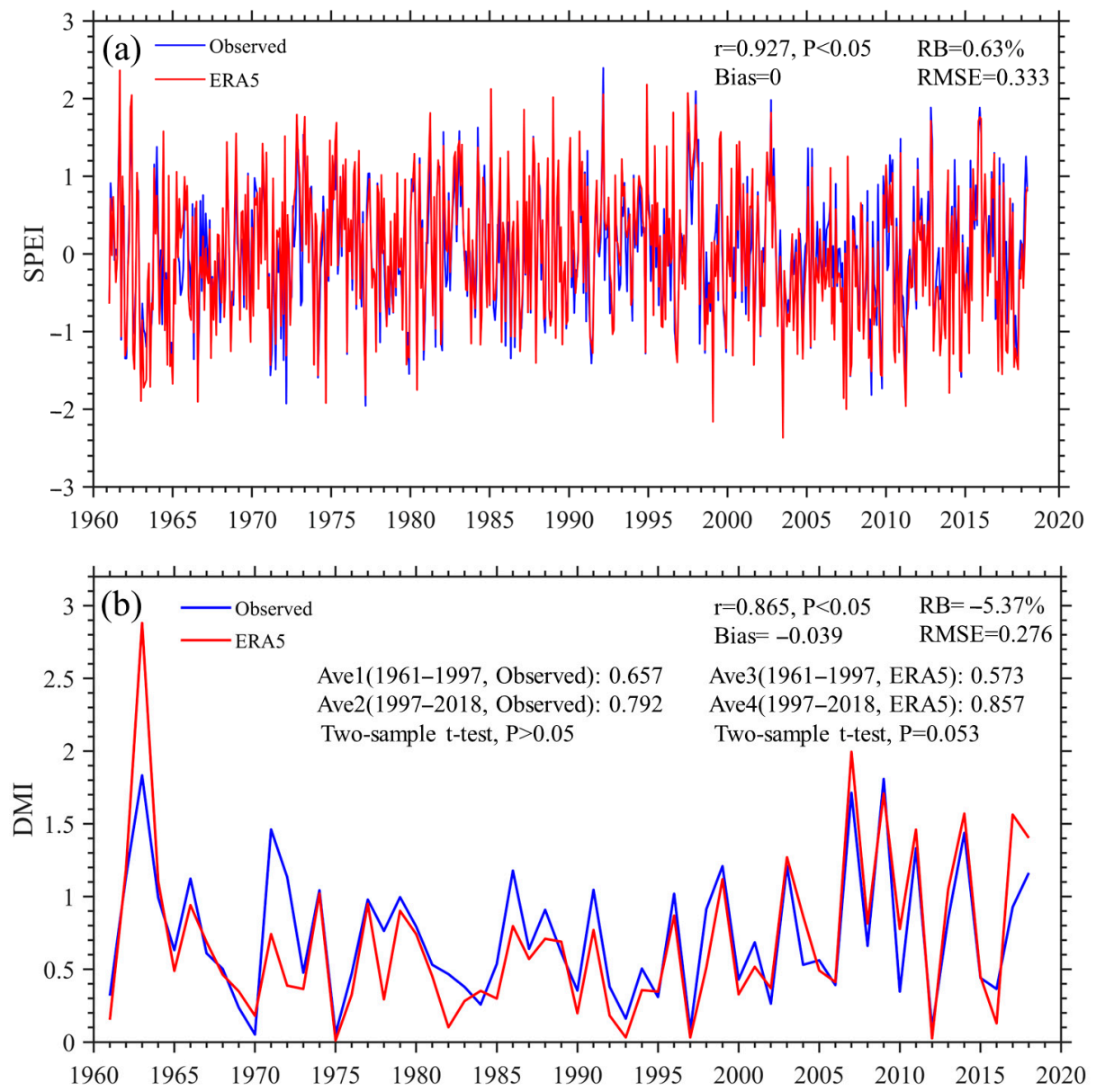

Figure 3. Temporal variations of (a) the 1-month SPEI and (b) the DMI per-year averaged GRB from 1961 to 2018.

Except in 1965 and 1966, the annual variations of heatwave frequency in the observations (Figure 4a) were relatively consistent with those in the ERA5 ( $r$ of $0.854, R B$ of $-0.02 \%$, and DISO of 0.227 ). The entire basin showed a significant upward trend at a rate of 0.25 (0.27 in ERA5) events/decade from 1961 to 2018. The heatwave frequency showed a downward trend from 1961 to 1997 and then a reversal (upward) trend from 1997 to 2018. 
The increasing rates of heatwave frequency (1.55 events/decade in the observation and 1.28 events/decade in the ERA5) during 1997-2018 were much greater than the decreasing rates before the turning point in 1997 . The average value of the heatwave frequency during 1997-2018 (5.214 events/year in the observations and 5.137 events/year in the ERA5) was significantly higher than during 1961-1997 (4.122 events/year in the observations and 4.182 events/year in the ERA5).
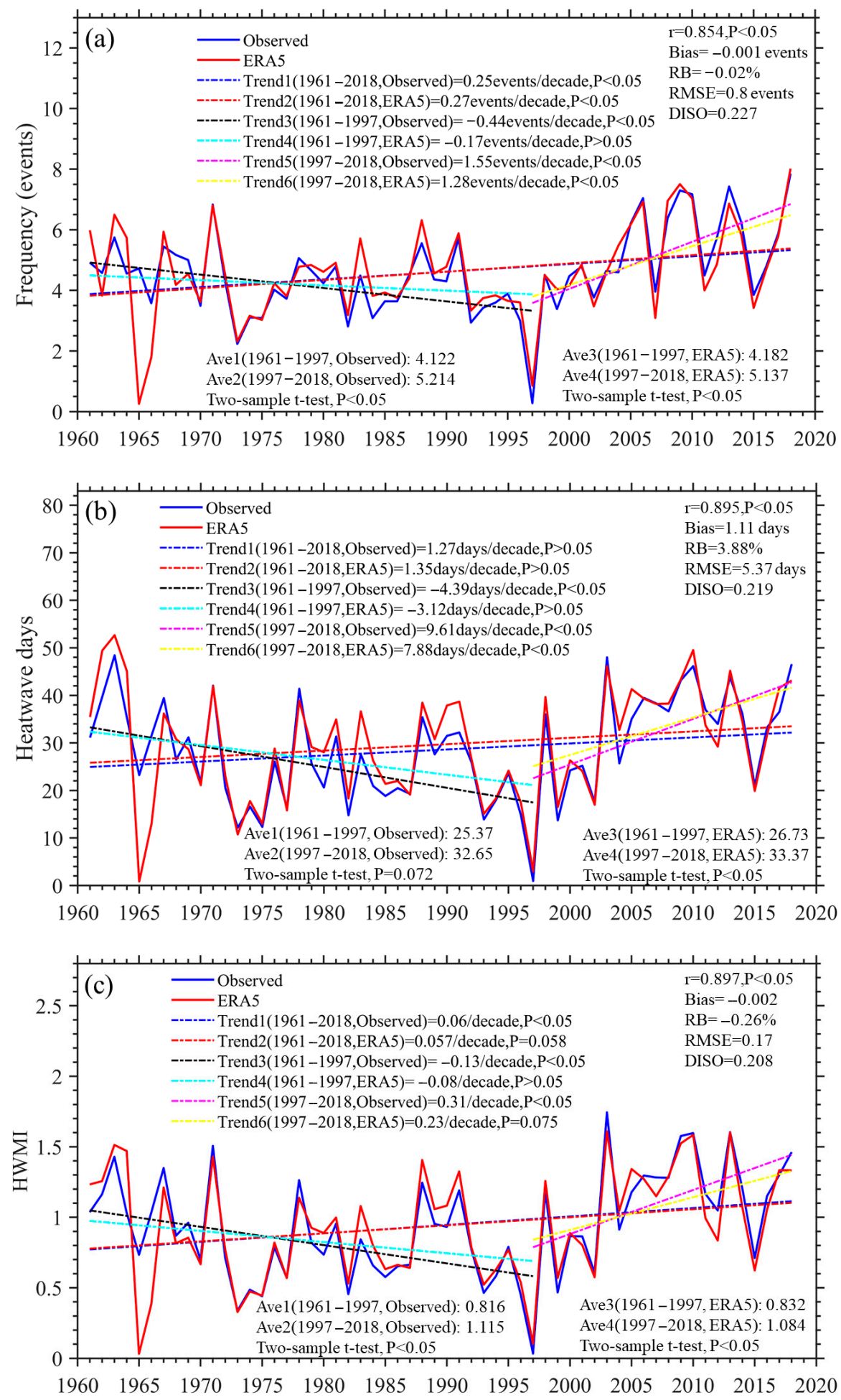

Figure 4. Temporal variations of (a) heatwave frequency, (b) heatwave days, and (c) HWMI per-year averaged GRB from 1961 to 2018. 
As shown in Figure 4b, the annual variations of heatwave days were similar to those of the frequency from 1961 to 2018. Thus, ERA5 effectively simulated the changes in the annual heatwave days, with an $r$-value of up to 0.895 , an $R B$ of $3.88 \%$, and a DISO of 0.219 . There was also a clear turning point around 1997 for heatwave days, i.e., a downward trend ( -4.39 days/decade in the observations and -3.12 days/decade in the ERA5) from 1961 to 1997, and a significant upward trend (9.61 days/decade in the observations and 7.88 days/decade in the ERA5) from 1997 to 2018. The average number of heatwave days during 1997-2018 was around seven days longer than that during 1961-1997 both in the observations and in ERA5, indicating a robust increase in the heatwave days in the GRB. The changes in the annual HWMI (Figure 4c) were similar to those of the heatwave frequency and heatwave days, with a decreasing trend ( $-0.13 /$ decade in the observations and -0.08/decade in the ERA5) from 1961 to 1997 and an increasing trend (0.31/decade in the observations and 0.23/decade in the ERA5) from 1997 to 2018. Both in the observations and in ERA5, the average value of the HWMI was significantly higher from 1997 to 2018 than that from 1961 to 1997 , indicating that the severity of the heatwave had increased in the GRB.

\subsection{CDHW Characteristics}

As shown in Figure 5a, ERA5 accurately reflected the annual variability of CDHW in the GRB $(r=0.834, R B=-0.73 \%$, and DISO $=0.527)$. The annual number of CDHW did not explicitly exhibit significant linear trends in the GRB from 1961 to 2018, but presented downward and upward trends during 1961-1997 and 1997-2018 (especially in ERA5), respectively. The annual mean number of CDHWs of the latter period (1997-2018) was larger than that of the earlier period (1961-1997), especially in ERA5, indicating more CDHWs in 1997-2018 relative to 1961-1997. There were more CDHWs both in the observations and ERA5 during the years 1962, 1963, 1964, 1991, 2003, 2007, 2009, and 2018. The variations of the annual CDHMI were similar to those of the CDHW frequencies, with average values of the CDHMI during 1997-2018 higher than those during 1961-1997 (Figure 5b). The highest value of the CDHMI existed in 2003 during 1961-2018.

CDHW frequency was 32-36 events in total from 1961 to 2018 (Figure 6a,b). Both in the observations and in ERA5, there were relatively high frequencies throughout the southern parts of the GRB. The mean differences of the CDHW frequency both in the observations and in ERA5 during 1997-2018 and 1961-1997 indicate that the values in the northern and southern regions were relatively higher than in the central regions (Figure $6 c, d$ ). This implies that there were increases in CDHWs in the northern and southern parts of the basin. Unlike the mean frequency differences in the observations, the mean frequency differences in ERA5 were basically positive in the entire basin, and approximately a quarter of the basin area showed substantial increases during 1997-2018 relative to 1961-1997. This indicates that the increasing trends of CDHWs in ERA5 were slightly greater than the observed value.

Figure 7 shows the spatial characteristics of D-H dependence. The higher the value of the D-H dependence index, the stronger the dependence relationship between droughts and heatwaves. Both in the observations and in ERA5, all the D-H dependence indices $\left(\mathrm{DH}_{\mathrm{F}}, \mathrm{DH}_{\mathrm{D}}\right.$, and $\left.\mathrm{DH}_{\mathrm{M}}\right)$ showed higher values of the spatial patterns in the southern parts of the basin than those in the northern parts of the basin, indicating that the interaction between the droughts and heatwaves in the southern part of the basin was stronger. The spatial characteristics of the three D-H dependence indices were similar but the overall order of the specific value was $\mathrm{DH}_{\mathrm{F}}<\mathrm{DH}_{\mathrm{D}}<\mathrm{DH}_{\mathrm{M}}$, which may have been caused by the frequency (number), duration, and magnitude of the event. The spatial characteristic of each D-H dependence index was roughly similar to the spatial characteristics of the $\mathrm{CDHW}$ frequency, indicating that higher values of the $\mathrm{D}-\mathrm{H}$ dependence indices are prone to producing more compound events. 

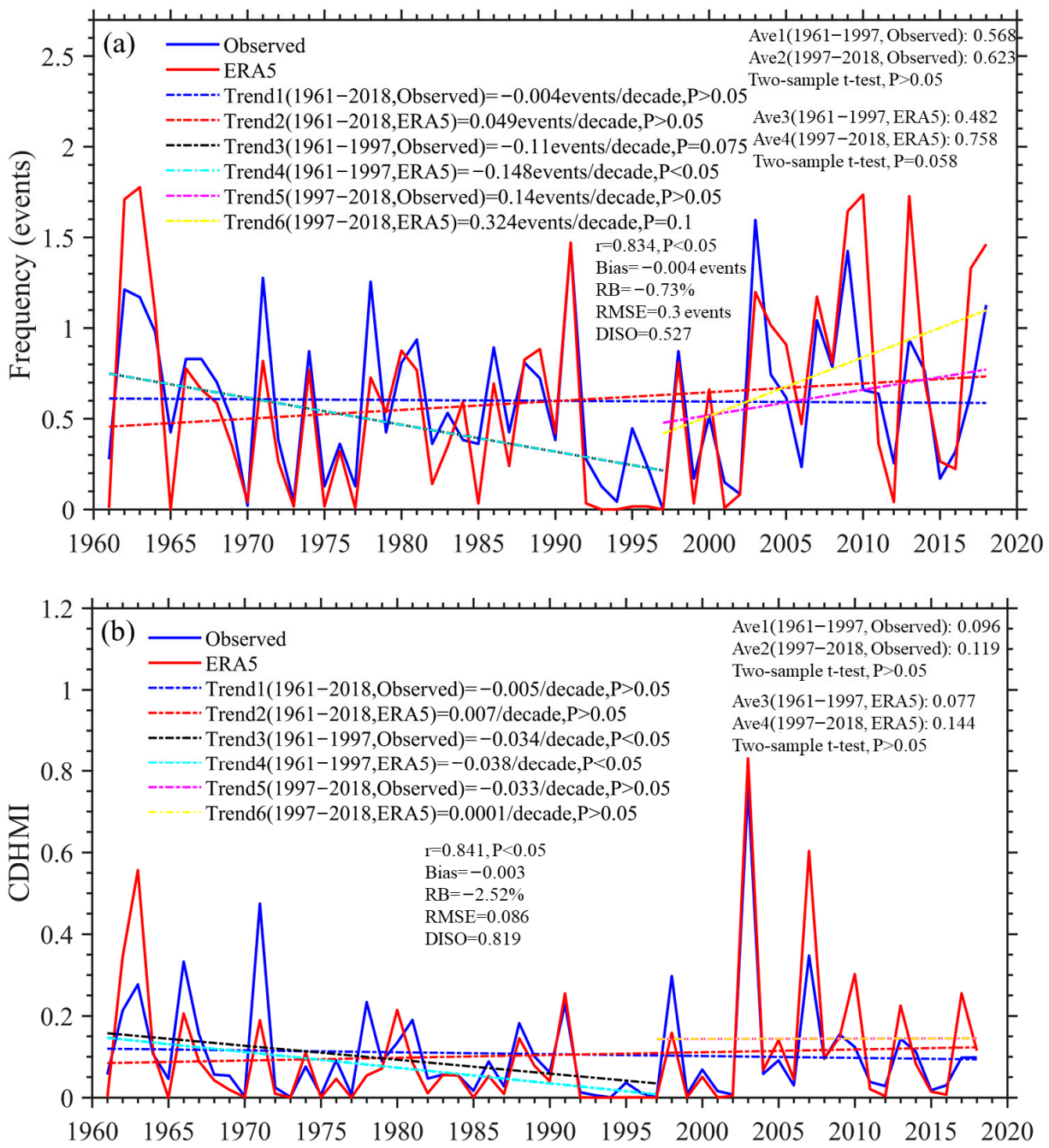

Figure 5. Annual variations of (a) CDHWs and (b) CDHMI per-year averaged GRB from 1961 to 2018.

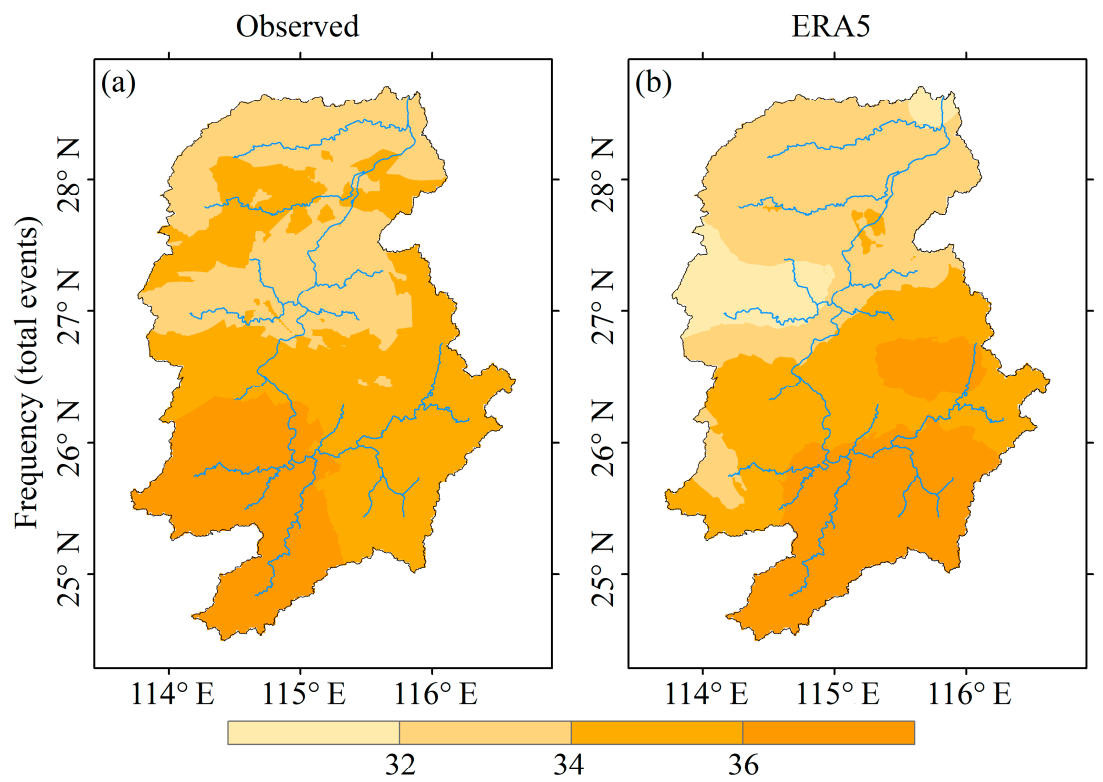

Figure 6. Cont. 


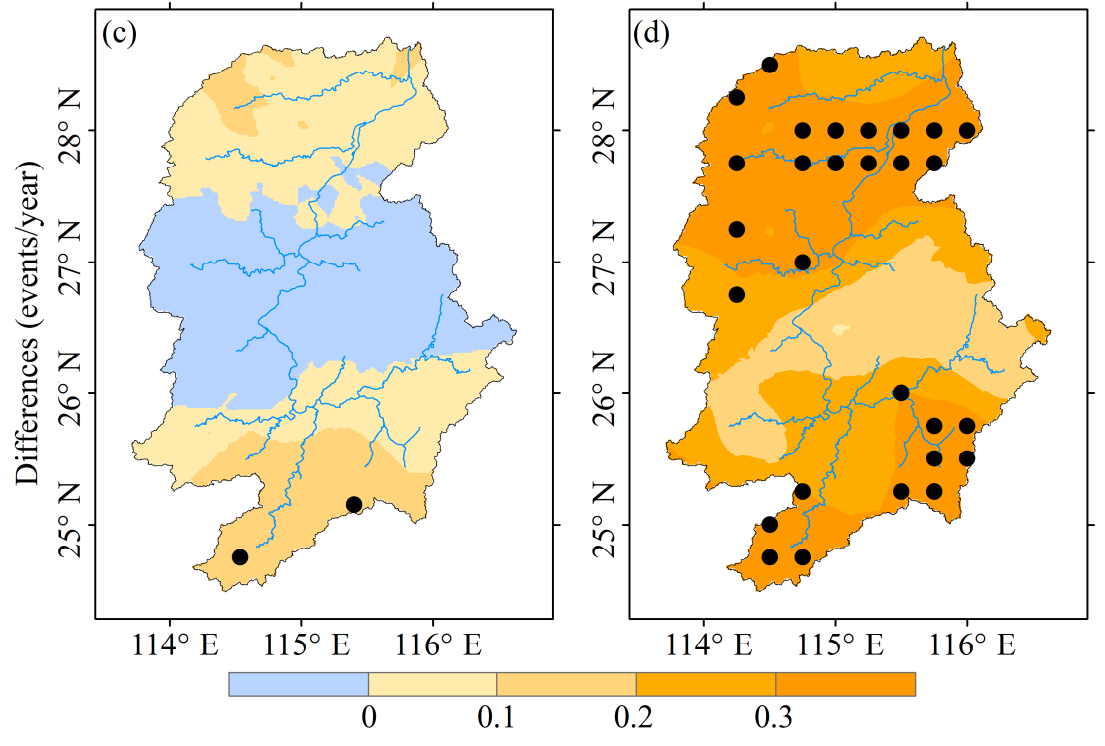

Figure 6. Spatial patterns of CDHW frequency in (a) the observations and (b) ERA5 from 1961 to 2018, and annual mean differences of CDHW frequency in (c) the observation and (d) ERA5 between 1997-2018 and 1961-1997, respectively. The solid black dots indicate passing the 0.05 significance level based on a two-sample t-test for equal means.
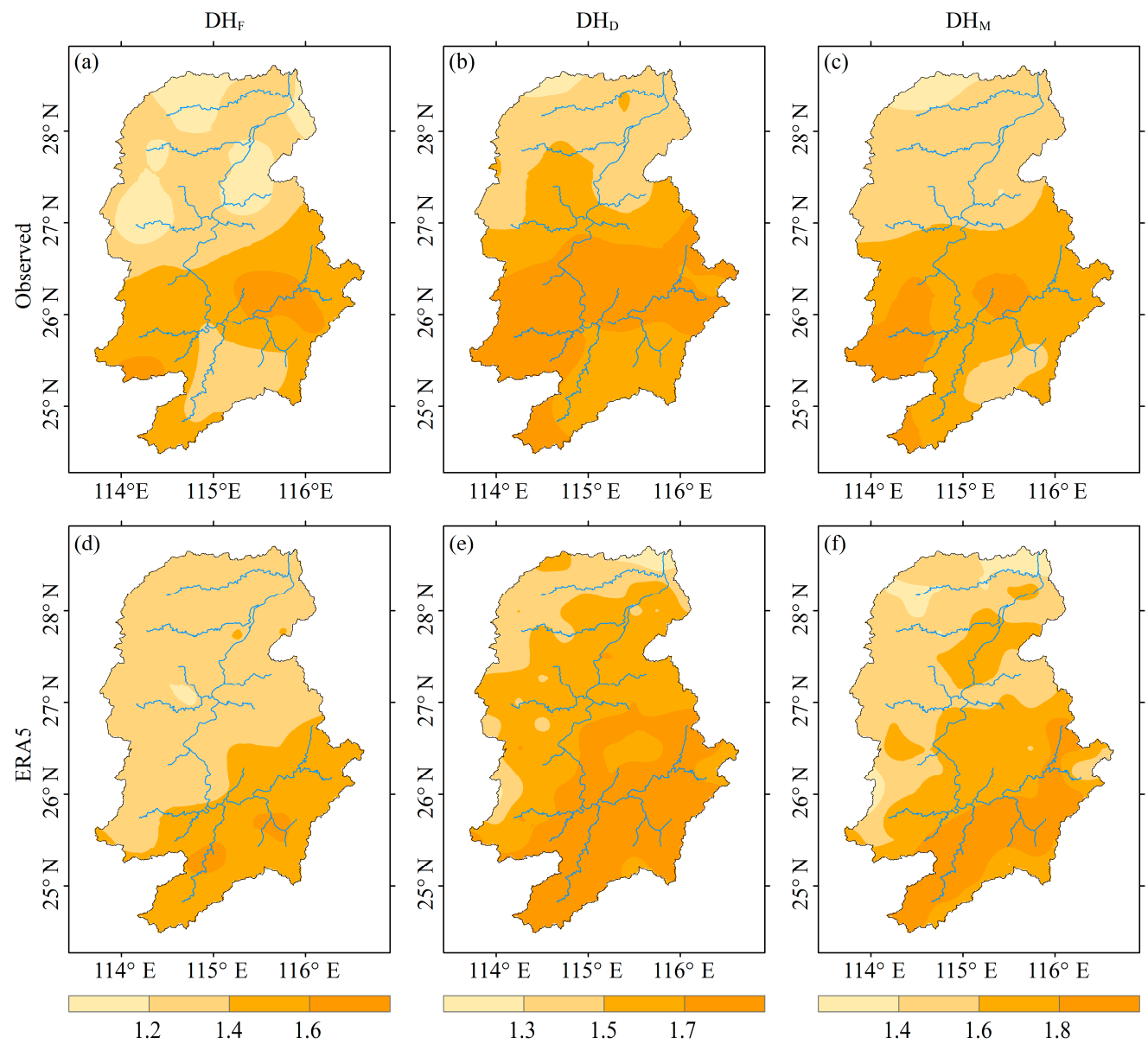

Figure 7. Spatial patterns of the D-H dependence indices for $(\mathbf{a}, \mathbf{d}) \mathrm{DH}_{\mathrm{F}},(\mathbf{b}, \mathbf{e}) \mathrm{DH}_{\mathrm{D}}$, and $(\mathbf{c}, \mathbf{f}) \mathrm{DH}_{\mathrm{M}}$ in the observations and ERA5 during 1961-2018. 
We extracted the CDHMI values of all CDHWs for all the stations/grids in the GRB from 1961 to 2018 to draw probability density curves via an empirical cumulative density function (CDF). As shown in Figure 8, the CDF curves in the observations and ERA5 basically coincided. The cumulative probabilities corresponding to the CDHMI values of $0.11,0.22$, and 0.4 were $0.5,0.75$, and 0.9 , respectively, and represented conditions of half, most, and almost all of the compound events, respectively. The occurrences of moderate, severe, extreme, and exceptional CDHWs correspond to probabilities of $50-100 \%, 25-50 \%, 10-25 \%$, and $<10 \%$, respectively. Thus, we divided the CDHWs into four magnitude grades: moderate $(0<\mathrm{CDHMI} \leq 0.11)$, severe $(0.11<\mathrm{CDHMI} \leq 0.22)$, extreme $(0.22<\mathrm{CDHMI} \leq 0.4)$, and exceptional $(\mathrm{CDHMI}>0.4)$.

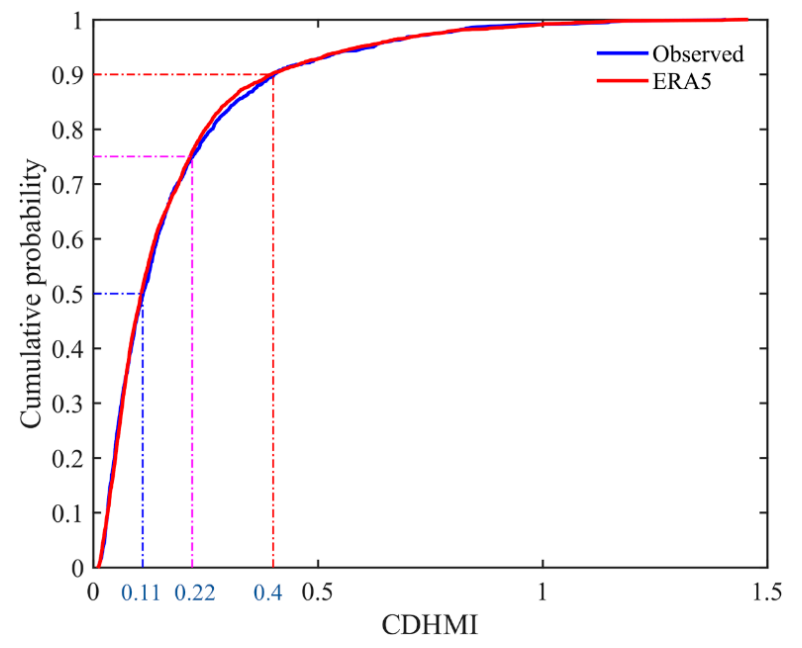

Figure 8. Empirical CDF of the CDHMI for all the CDHWs at all the stations/grids in the observation/ERA5 in the GRB from 1961 to 2018.

In order to further explore the relationship between droughts and heatwaves, we analyzed their characteristics under different grades (magnitudes) of CDHWs (Figure 9). In the case of moderate CDHWs, the SPEI value was around -1.3 (Figure 9a) and the number of heatwave days was around 8 days (Figure $9 \mathrm{~b}$ ) in the observations and ERA5. When the SPEI value was as low as -1.5 (Figure 9a), the number of heatwave days increased to about 16 days (Figure $9 \mathrm{~b}$ ) under severe CDHWs. Under extreme CDHW conditions, the SPEI value was further decreased to about -1.7 (Figure 9a) and the heatwave days increased to about 21 days (Figure 9 b).

Under moderate, severe, and extreme CDHWs, the SPEI values and the heatwave days (box range and median) in the observations were basically the same as in ERA5. Under exceptional CDHW conditions, the SPEI values (Figure 9a) in ERA5 (the box range is -2 to -2.3 ) were lower than the observed values (the box range is -1.8 to -2.1 ), whereas the heatwave days (Figure 9b) in ERA5 were only two days higher than in the observations (the median value was around 30 days). As the CDHMI increased, the SPEI value gradually decreased and the number of heatwave days gradually increased, indicating that the large CDHMI could be attributed to the enhanced interaction between droughts (lower SPEI) and heatwaves (longer duration) during the specific periods. In general, the drought severities and the number of the heatwave days reflected by ERA5 were slightly greater than those in the observations.

\subsection{Population Exposure to $\mathrm{CDHWs}$}

The population of the six prefecture-level cities in the GRB showed significant increasing trends (Figure 10), with a growth rate of 0.614 million/decade in Nanchang, 0.328 million/decade in Yichun, 0.074 million/decade in Xinyu, 0.107 million/decade in Pingxiang, 0.214 million/decade in Ji'an, and 0.547 million/decade in Ganzhou. The population of Ganzhou, Nanchang, and Yichun cities all exceeded 5 million at the end of 
2018, especially Ganzhou city (with a population of 8.68 million). From the perspective of population and administrative area, Nanchang city had the highest population density (as well as the highest growth rate) among these cities in the GRB.
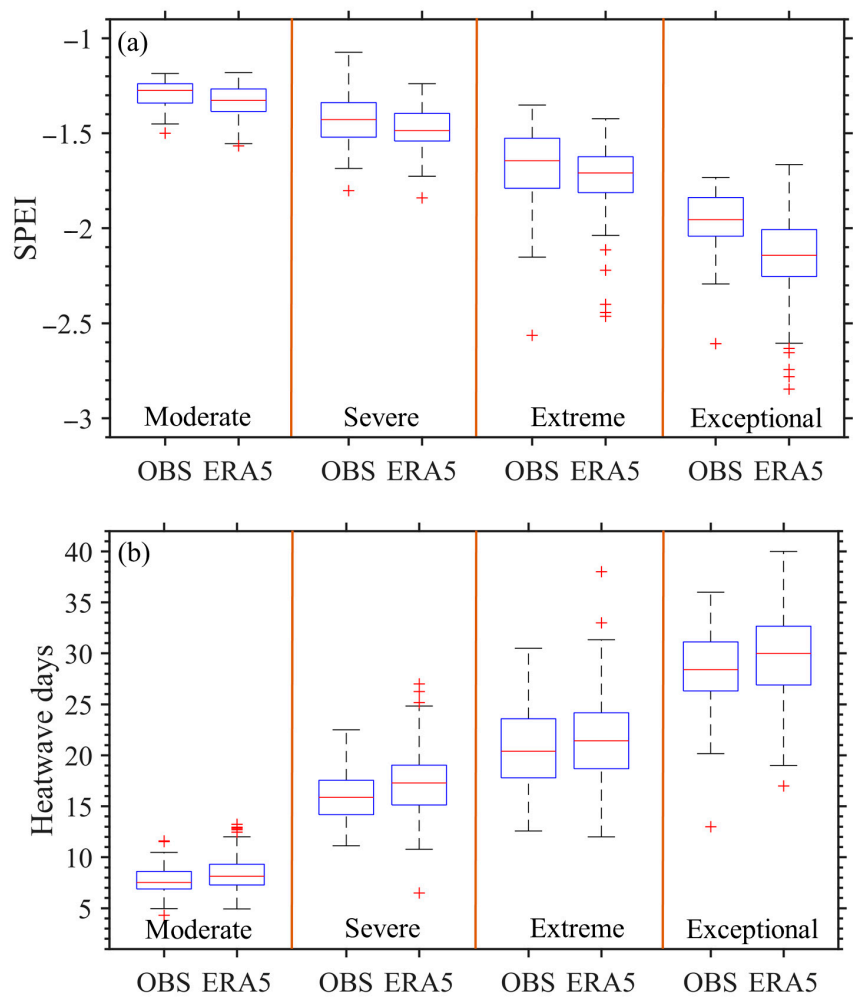

Figure 9. (a) SPEI values and (b) heatwave days under CDHW conditions at moderate, severe, extreme, and exceptional grades, relatively in the GRB during 1961-2018.
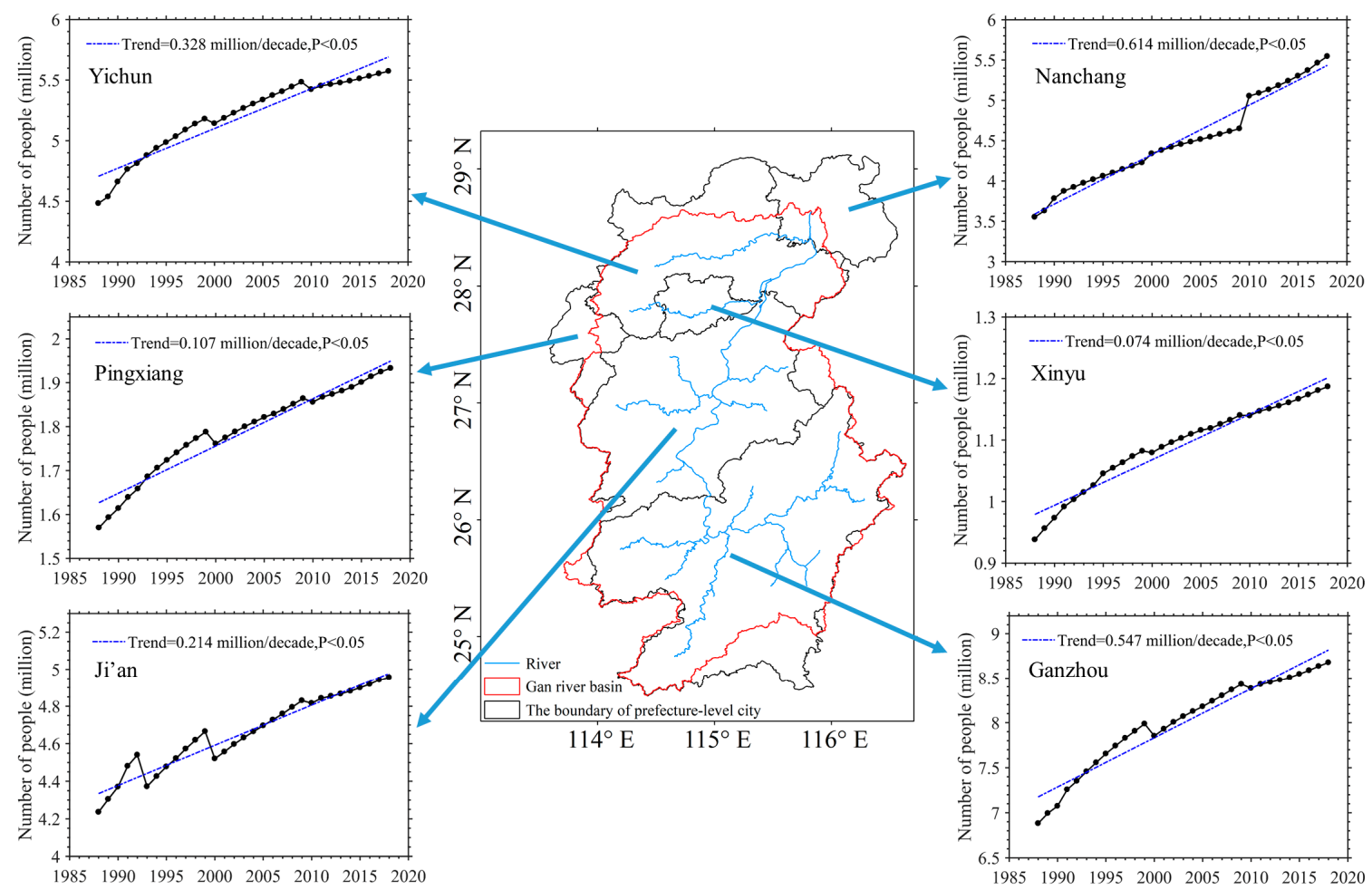

Figure 10. Annual population variations from 1988 to 2018 at the prefecture-level city scale in the GRB. 
We investigated the annual variability of the overall population exposure to the CDHW frequency and CDHMI in the GRB. Although the CDHW frequency exposure in ERA5 was slightly overestimated, the annual changes of frequency exposure in ERA5 were basically similar to the observations (Figure 11a). The annual CDHW frequency exposure showed an increasing trend both in the observations and in ERA5 in the GRB from 1988 to 2018. For example, the CDHW frequency exposure in the observations (ERA5) increased by about 1.67-fold (2.2-fold) from 18 (18) million person-days in 1988 to 30 (40) million person-days in 2018, indicating a robust increase in the CDHW frequency exposure in the GRB during 1988-2018. The increasing rate of CDHW frequency exposure in ERA5 (7.03 million personevents/decade) was approximately double than that in the observations (3.18 million person-events/decade). Annual variation of the CDHMI exposure in ERA5 was consistent with the observations (Figure 11b), both showing slight upward trends. The CDHMI exposures in 2003 and 2007 were much higher than in other years, indicating that a large number of people were exposed to severe compound events in these two years. In general, annual population exposure to the CDHW frequency and CDHMI all showed increasing trends, with higher values in the years 1991, 2003, 2007, and 2013.
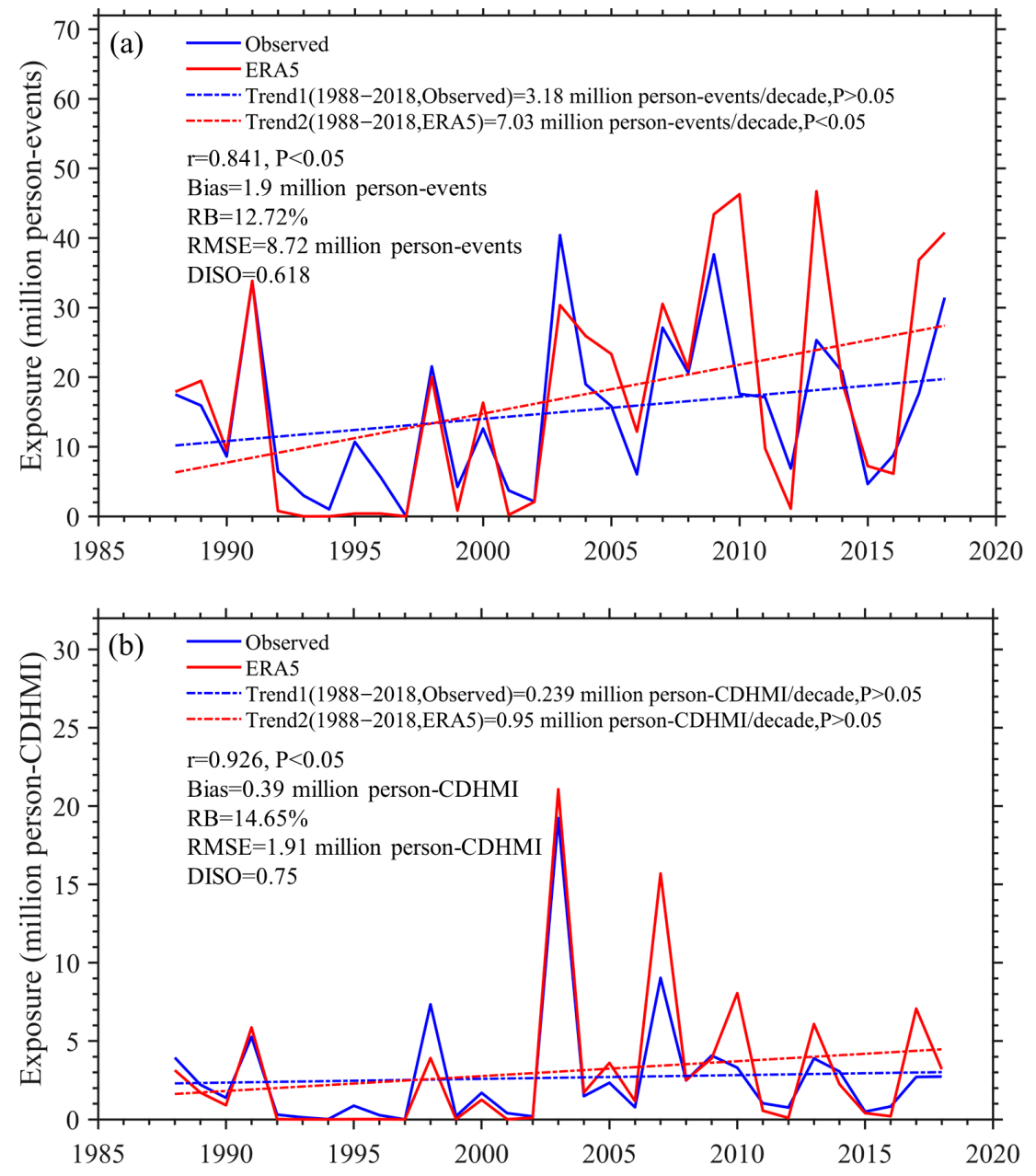

Figure 11. Variations of annual population exposure to (a) CDHW frequency and (b) CDHMI from 1988 to 2018 in the GRB.

ERA5 reasonably reflected the characteristics of population exposure to the CDHW frequencies at different grades (Figure 12). The ERA5 simulation effect $(r=0.85$ and $D I S O=0.779$ ) of population exposure to moderate CDHW events (Figure 12a) was better than that of the other three grade levels. Moderate CDHW exposure showed a significant increasing trend in observations and ERA5, and the upward trend in ERA5 was about 1.5 times the observation. The increasing trend of severe CDHW exposure in ERA5 was 
1.76 million person-events/decade, which was obviously higher than the observed value of 0.383 million person-events/decade (Figure 12b). There was no obvious upward or downward trend in the exposure of extreme and exceptional CDHWs, but the inter-annual fluctuations were relatively large (Figure 12c,d). In general, ERA5 had a greater upward trend than the observed value when it reflected the characteristics of population exposure to the CDHW frequencies at different grades.
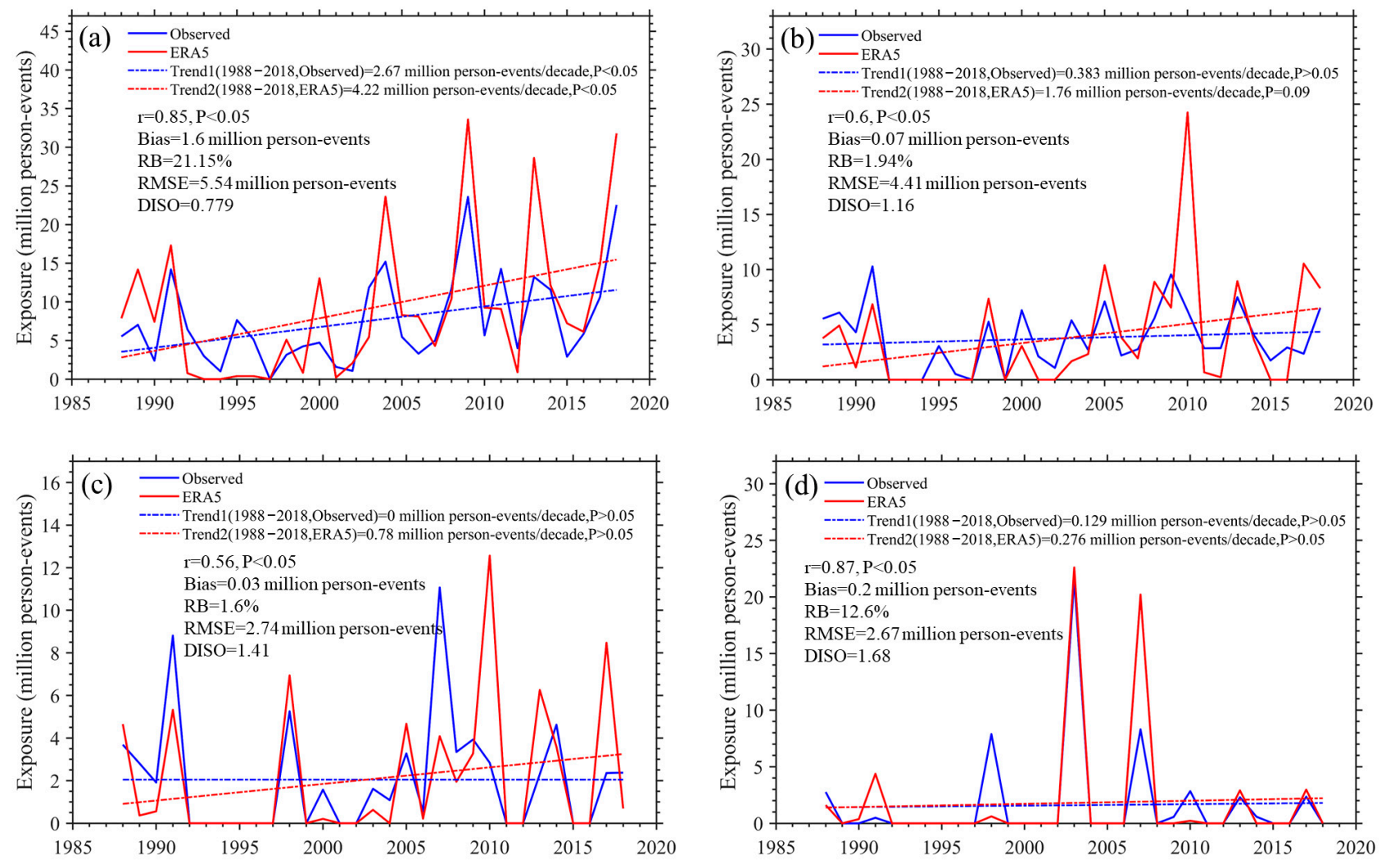

Figure 12. Variations of annual population exposure to (a) moderate, (b) severe, (c) extreme, and (d) exceptional CDHW frequencies from 1988 to 2018 in the GRB.

In order to facilitate comparative analysis, we divided the exposure study period into three decades, namely, 1989-1998 $\left(\mathrm{T}_{1}\right), 1999-2008\left(\mathrm{~T}_{2}\right)$, and 2009-2018 $\left(\mathrm{T}_{3}\right) . \mathrm{T}_{2-1}$ represents the change in the $T_{2}$ period relative to the $T_{1}$ period. $T_{3-2}$ and $T_{3-1}$ follow the same rule. As shown in Table 1, for the moderate CDHW frequency exposure, the exposure increased by $26 \%\left(62 \%\right.$ in ERA5) from $\mathrm{T}_{1}$ to $\mathrm{T}_{2}$, and increased by $79 \%\left(102 \%\right.$ in ERA5) from $\mathrm{T}_{2}$ to $\mathrm{T}_{3}$. The moderate CDHW frequency exposure increased by 6.39 million person-events (10.67 million person-events in ERA5) from $\mathrm{T}_{1}$ to $\mathrm{T}_{3}$, with a rate of $127 \%(227 \%$ in ERA5). Severe CDHW frequency exposure also presented an upward trend both in the observations and in ERA5 during the past three decades, but its upward rate was less than the moderate CDHW frequency exposure. The extreme and exceptional frequency CDHW exposures in the observations had smaller changes of -0.05 million person-events $(-3 \%)$ and 0.07 million person-events $\left(9 \%\right.$ ) from $\mathrm{T}_{1}$ to $\mathrm{T}_{3}$. However, the extreme and exceptional frequency CDHW exposures in ERA5 showed a larger increase in $T_{3}$ relative to $T_{1}$, especially for extreme grade, with a change of 2.2 million person-events $(169 \%)$. The total exposure increased by $40 \%(89 \%)$ from $\mathrm{T}_{1}$ to $\mathrm{T}_{2}$, and by $25 \%(60 \%)$ from $\mathrm{T}_{2}$ to $\mathrm{T}_{3}$. The total exposure showed a substantial increase from $\mathrm{T}_{1}$ to $\mathrm{T}_{3}$, with an increment of 8.09 (17.23) million person-events and a rate of $76 \%(201 \%)$ in observation (ERA5). 
Table 1. Population exposure to CDHW frequency and the change rates.

\begin{tabular}{|c|c|c|c|c|c|c|}
\hline & \multicolumn{3}{|c|}{$\begin{array}{l}\text { CDHW Frequency Exposure } \\
\text { (Million Person-Events) }\end{array}$} & \multicolumn{3}{|c|}{ Change Rate (\%) } \\
\hline & $\begin{array}{c}\mathrm{T}_{1} \\
\text { Obs (ERA5) }\end{array}$ & $\begin{array}{c}\mathrm{T}_{2} \\
\text { Obs (ERA5) }\end{array}$ & $\begin{array}{c}\mathrm{T}_{3} \\
\text { Obs (ERA5) }\end{array}$ & $\begin{array}{c}\mathrm{T}_{2-1} \\
\text { Obs (ERA5) }\end{array}$ & $\begin{array}{c}\mathrm{T}_{3-2} \\
\text { Obs (ERA5) }\end{array}$ & $\begin{array}{c}\mathrm{T}_{3-1} \\
\text { Obs (ERA5) }\end{array}$ \\
\hline Moderate & $5.05(4.7)$ & $6.38(7.61)$ & 11.44 (15.37) & $26(62)$ & 79 (102) & $127(227)$ \\
\hline Severe & $3(2.04)$ & $3.52(3.17)$ & $4.68(6.33)$ & $17(55)$ & $33(100)$ & $56(210)$ \\
\hline Extreme & $1.9(1.3)$ & $2.22(1.16)$ & $1.85(3.5)$ & $17(-11)$ & $-17(202)$ & $-3(169)$ \\
\hline Exceptional & $0.8(0.54)$ & $2.98(4.24)$ & $0.87(0.61)$ & $273(685)$ & $-71(-86)$ & $9(13)$ \\
\hline All & $10.75(8.58)$ & $15.1(16.18)$ & $18.84(25.81)$ & 40 (89) & $25(60)$ & $76(201)$ \\
\hline
\end{tabular}

We decomposed the exposure change to evaluate the relative contributions of climate, population, and joint change effects. As shown in Figure 13, we found that the contribution of the climate change effect was the largest (over $68 \%$ ), even reaching $73.87 \%$ in $\mathrm{T}_{2-1}$, whereas the contribution of the joint change effect was the lowest (below 11\%) in the observed CDHW frequency exposure. The CDHW frequency contributions of ERA5 were similar to those in the observations, but the contributions of the climate change effect were larger (reaching about $80 \%$ ) than in the observations, and the contributions of the population change effect were about $10 \%$ lower than in the observations. For the CDHMI exposure, the contributions of climate change both in the observations and ERA5 showed straight downward trends during $\mathrm{T}_{2-1}, \mathrm{~T}_{3-2}$, and $\mathrm{T}_{3-1}$. We found that population growth was responsible for $52.88 \%$ of the CDHMI exposure in $\mathrm{T}_{3-1}$, which showed a large difference in ERA5 (population change effect of $10.02 \%$ ).
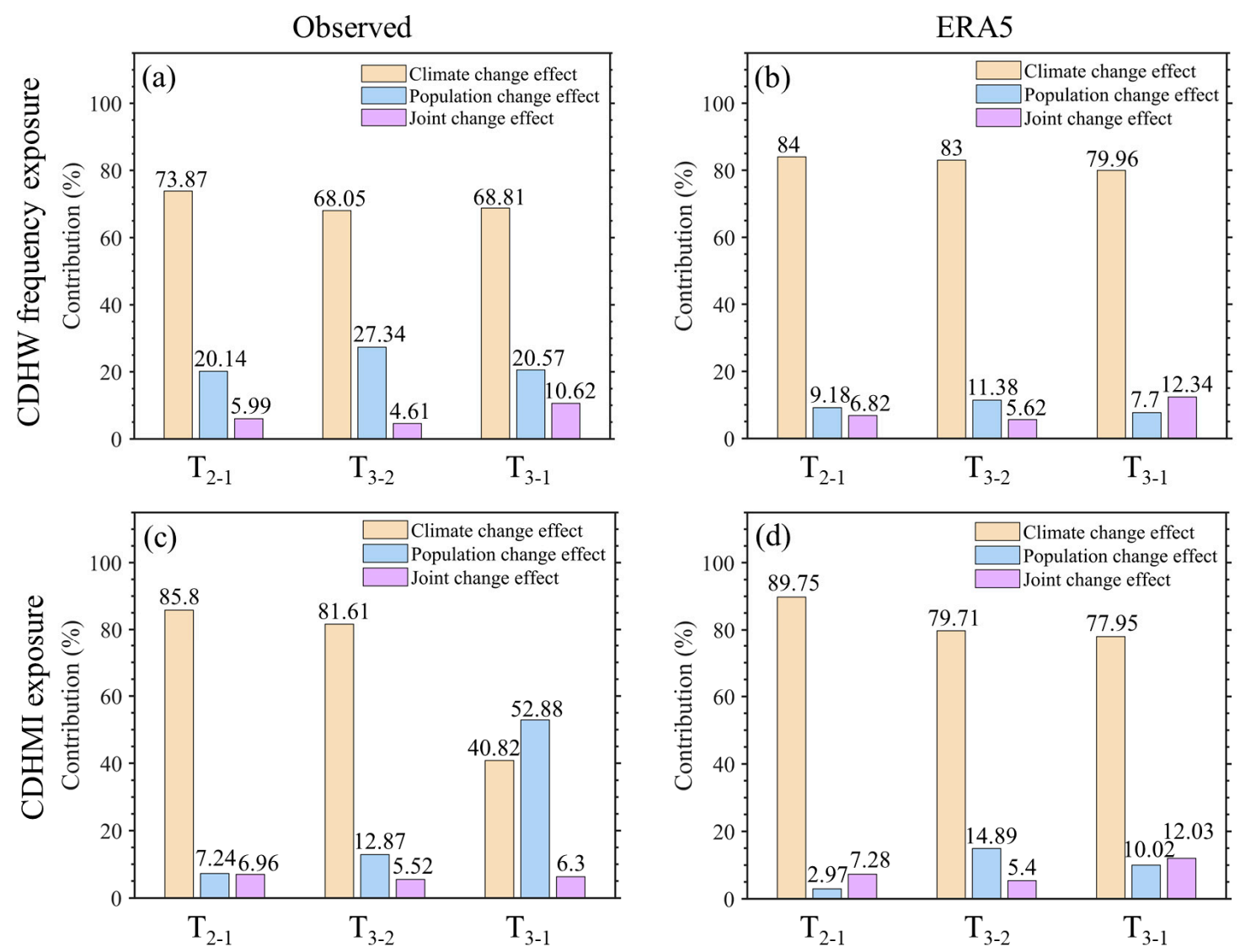

Figure 13. Decomposition of the change in population exposure to (a,b) CDHW and (c,d) CDHMI in the GRB. $\mathrm{T}_{2-1}, \mathrm{~T}_{3-2}$, and $\mathrm{T}_{3-1}$ represent the contributions of changes in 1999-2008, 2009-2018, and 2009-2018 relative to 1989-1998, 1999-2008, and 1989-1998, respectively. 
We further analyzed the contributions of CDHW frequency exposures at different grades in different periods (Figure 14). In general, the climate change effect was the main contributor, followed by the population change effect, and finally the joint change effect. In moderate CDHW frequency exposures, the contributions of climate change were more than $60 \%$, and even exceeded $80 \%$ in ERA5. In $\mathrm{T}_{3-1}$, the contribution of climate change for moderate CDHW frequency exposure was $76 \%$ (81\% in ERA5), and the population and joint change effects were of similar magnitude (about 10\%). In the observations of severe CDHW frequency exposures, the contributions of climate change effect were still high, but their magnitude was about $10 \%$ lower than that of moderate events. Compared to the severe CDHW frequency exposures, the contributions of climate change and population change effects for extreme CDHW frequency exposures were basically the same magnitude (about $45 \%$ ) in $\mathrm{T}_{3-1}$, but ERA5 did not capture those effects well. In the exceptional CDHW frequency exposures, ERA 5 and observations showed similar characteristics. In $\mathrm{T}_{2-1}$ and $\mathrm{T}_{3-2}$, the contributions of climate change effects both in the observations and ERA5 were much higher than the contributions of the population and joint change effects. In $T_{3-1}$, the population contributions (68\% in the observations and 79\% in ERA5) were much higher than the contributions of the climate and joint change effects. Both the observations and ERA5 in $\mathrm{T}_{3-1}$ showed that the contributions of population change effects gradually increased with the increase in CDHMI, whereas the contributions of climate change and joint change effects gradually decreased with the increase in CDHMI.

\subsection{Case of 2003 CDHWs}

The CDHMI exposure value in 2003 was much higher than in other years, so we isolated a case analysis of the 2003 CDHWs. The heatwave days during the summer of 2003 in the GRB were the longest (44.5 days) in the observations (the summer heatwave days in ERA5 ranked second, up to 44.2 days) since 1961 (Figure 15a,b). In the summer of 2003, precipitation in the GRB was only $342.5 \mathrm{~mm}$ in the observations (386.1 $\mathrm{mm}$ in ERA5), which was about $60 \%$ of its multi-year average summer precipitation (Figure $15 \mathrm{c}, \mathrm{d}$ ). The average one-month SPEI values in the summer of 2003 were -0.96 in the observations and -1.11 in ERA5 (Figure 15e,f). The July SPEI values in 2003 were as low as -1.97 in the observations and -2.37 in ERA5 (Figure 15g,h), and these values indicate that the GRB experienced the worst extreme droughts in the summer of 2003. The relatively long-term high temperatures and the extreme precipitation deficits (extreme droughts) in the summer of 2003 led to exceptional CDHWs, which caused economic losses directly tied to agricultural production by several billion $\mathrm{CNY}$ at least $[52,53]$, and also caused significant stress on the ecosystem and human health.

We conducted the composite of the atmospheric circulation anomalies (Figure 16) for July of 2003 due to the most serious CDHWs in the GRB during July of 2003. High positive values in $500 \mathrm{hPa}$ geopotential height anomalies driven by the strong subtropical high (5 $880 \mathrm{gpm}$ ) during July of 2003 over the GRB (Figure 16a) caused the air to sink and increase temperature, which means that heatwaves were prone to occur. As shown in Figure 16b, the anticyclone anomaly center near the GRB suppressed precipitation due to the relatively large positive values of water vapor flux divergence anomalies, which likely made the basin prone to droughts. It was extremely difficult to produce precipitation under the specific conditions of large positive anomalies of convective inhibition (Figure 16c, negative anomalies of total cloud cover over about half of the GRB) and surface net solar radiation (Figure 16d), which eventually led to the exceptional CDHW in the summer of 2003. 

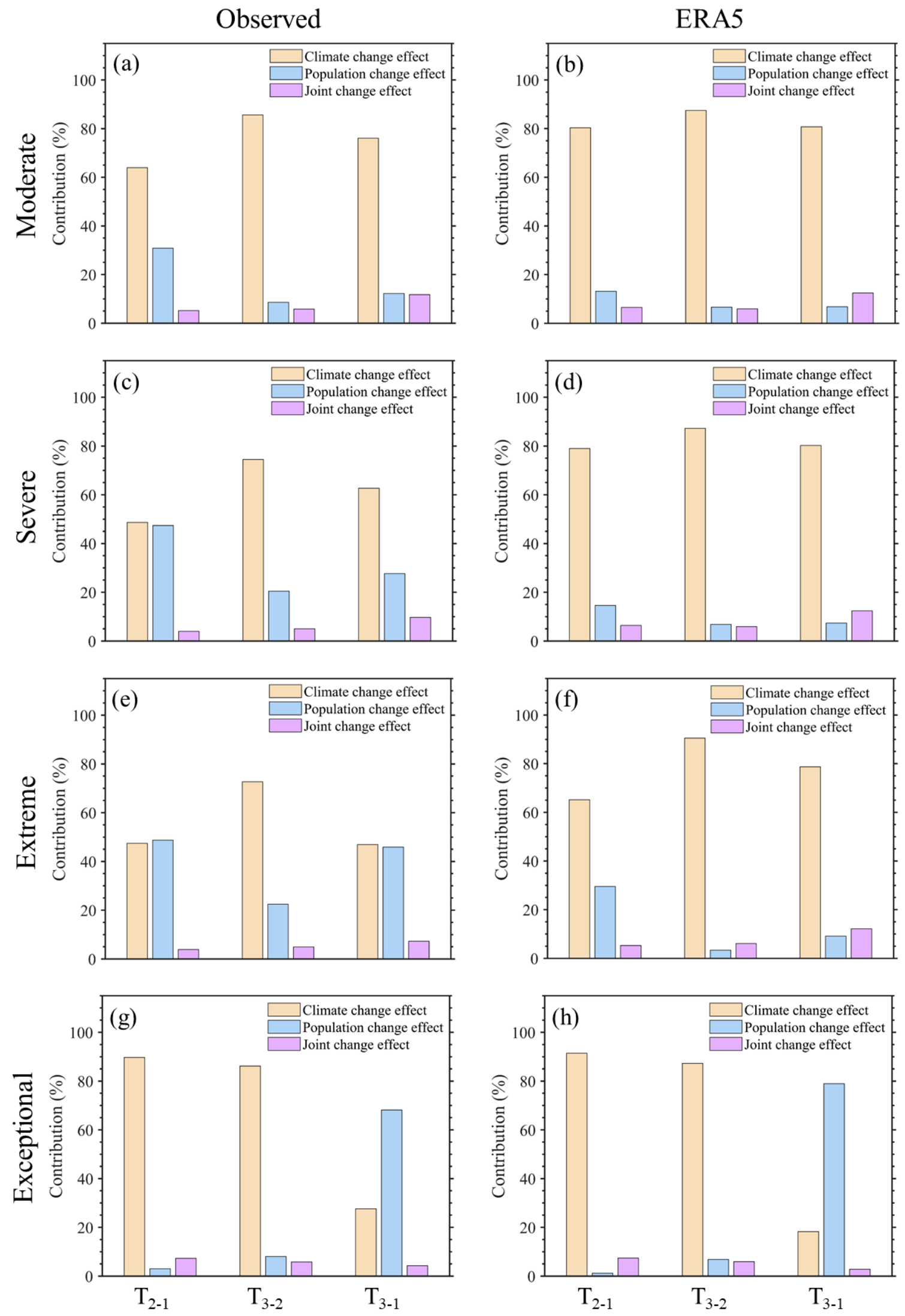

Figure 14. The same as Figure 13, but for CDHW frequency exposure at $(\mathbf{a}, \mathbf{b})$ moderate, $(\mathbf{c}, \mathbf{d})$ severe, $(\mathbf{e}, \mathbf{f})$ extreme, and $(\mathbf{g}, \mathbf{h})$ exceptional grades. 
Observed
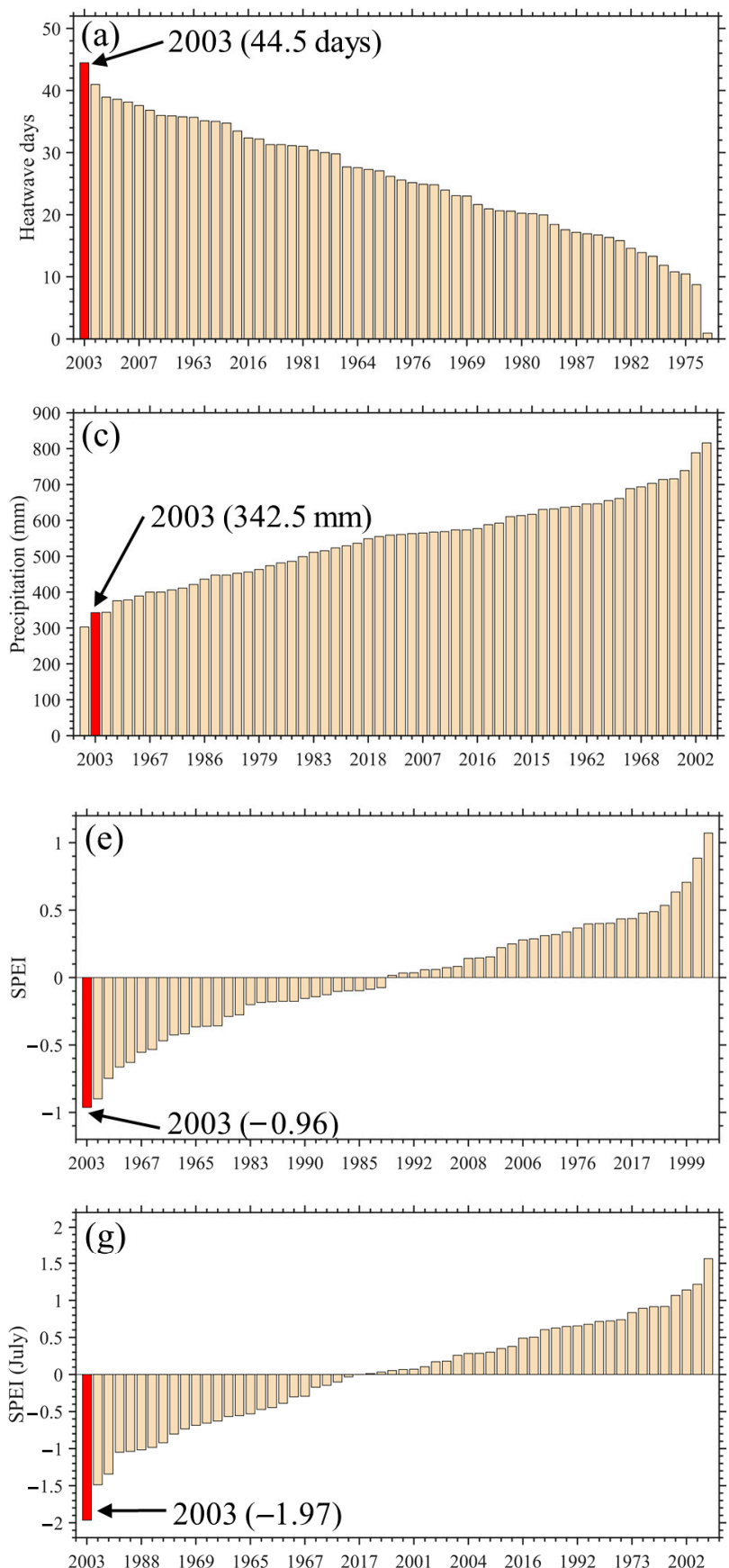

ERA5
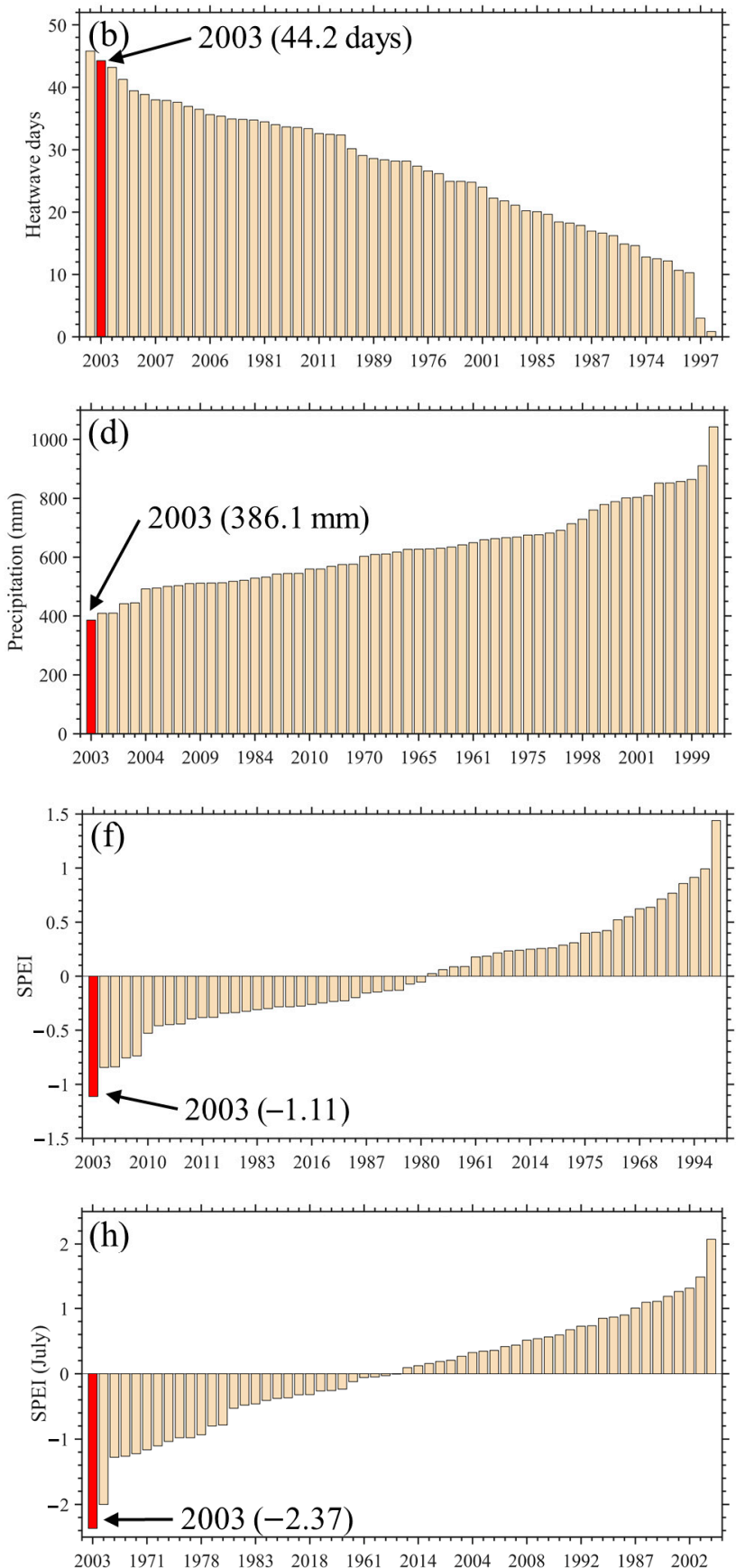

Figure 15. Rank-average during June-August of $(\mathbf{a}, \mathbf{b})$ heatwave days, $(\mathbf{c}, \mathbf{d})$ precipitation, $(\mathbf{e}, \mathbf{f})$ SPEI values, and $(\mathbf{g}, \mathbf{h})$ rank for the July SPEI values in the GRB from 1961 to 2018. 

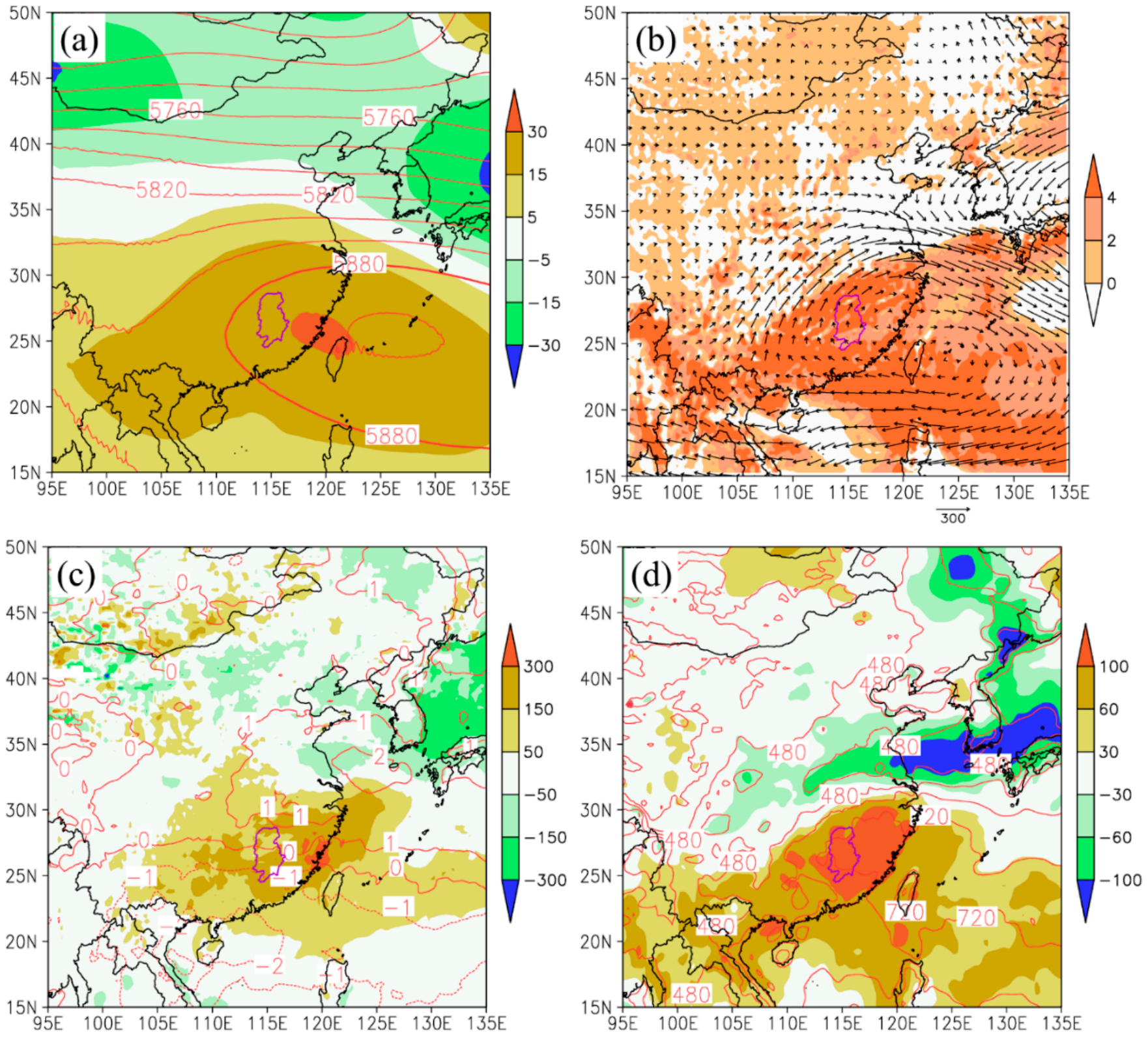

Figure 16. Spatial patterns of (a) the $500 \mathrm{hPa}$ geopotential height (contour, gpm) and its anomalies (shaded, gpm), (b) integrated layer water vapor flux anomalies (vector, $\mathrm{kg} \cdot \mathrm{m}^{-1} \cdot \mathrm{s}^{-1}$ ) and divergence anomalies ( $\mathrm{shaded}, 10^{-5} \mathrm{~kg} \cdot \mathrm{m}^{-2} \cdot \mathrm{s}^{-1}$ ), (c) convective inhibition (shaded, $\mathrm{J} \cdot \mathrm{kg}^{-1}$ ) and total cloud cover anomalies (contour, 0-10 tenths), and (d) surface net solar radiation (contour, $\mathrm{MJ} / \mathrm{m}^{2}$ ) and its anomalies (shaded, $\mathrm{MJ} / \mathrm{m}^{2}$ ) for July 2003 . The anomaly values for July 2003 are relative to July 1961-2018.

\section{Discussion}

CDHWs can amplify the damage of the individual droughts and heatwaves, ultimately wreaking a catastrophic effect on the environment, society, economy, and human health [44,54]. The summer CDHWs in Europe in 2003 and China in 2013 caused a high increase in mortality, especially in the elderly and infant populations as well as in persons with pre-existing cardiovascular and respiratory conditions $[9,11,34,36,55]$. In this study, we used the GRB, a subtropical region in southern China (heatwaves and droughts are prone to occur in summer in this region), as an example to investigate characteristics of population exposure to CDHWs based on observation and ERA5 data.

ERA5 had a slight overestimation for the precipitation in the GRB, which is similar to the findings of previous studies [30,32]. This may be because ERA5 tends to overestimate 
the light precipitation events, which makes the proportion of light precipitation events in the total precipitation events relatively high [56]. In most parts of China, light precipitation days accounted for more than $60 \%$ of all precipitation days [56,57]. ERA5 slightly overestimated the $T_{\text {mean, }}$ and slightly underestimated the $T_{\max }$ in the GRB, which is similar to the results of a previous study in Southeast Asia [58]. The ability of ERA5 to simulate the $\mathrm{T}_{\text {mean }}$ was slightly better than its ability to simulate the $\mathrm{T}_{\max }$. This may have been due to the fact that we derived the daily $\mathrm{T}_{\max }$ that came from hourly data, which ignored the information of the sub-hourly extreme temperatures. In short, ERA5 can better reflect the characteristics of temperature and precipitation in the GRB.

ERA5 was more effective at simulating the one-month SPEI values and droughts in the GRB. The average magnitude of the droughts during 1997-2018 was slightly higher than that in 1961-1997. For the frequency, duration, and magnitude of heatwaves, ERA5 also had good applicability in the GRB. Heatwaves showed significant increasing trends from 1997 to 2018 in the observations and ERA5, which may have been caused by the greater warming after the 1990s than before the 1990s [22,36]. For the frequency and the magnitude of CDHWs, ERA5 performed well in simulating their annual variation characteristics, with $r$-values above 0.8 and an $R B$ within $3 \%$. The average frequency and magnitude of CDHWs during 1997-2018 were relatively larger than during 1961-1997, especially in ERA5, which may have been caused by the increase in the number of individual droughts and heatwaves in the GRB.

The East Asian summer monsoon (EASM) is characterized by the northward movement of the subtropical high frontal zone and the associated rain belt during the early summer months through the late summertime in China, and it includes two abrupt jumps associated with the Meiyu season [59]. The location and duration of the rain belt have a significant impact on regional floods and droughts. If the EASM weakens, causing its northward movement to be insufficient, southern China becomes prone to flood disasters due to the rain belt remaining in this region for a long period. In contrast, if the rain belt jumps to the north too early (i.e., a strong EASM) and remains in northern China for a long period, floods are likely to occur in northern China and droughts are likely to occur in southern China (e.g., the GRB). Global warming, multi-decade/multi-annual variability (e.g., Pacific Decadal Oscillations or El Niño-Southern Oscillations), and intraseasonal variability can also affect the location and duration of the rain belt [20,60-62], thereby affecting the CDHW characteristics in the GRB.

Analysis of the 2003 CDHWs in the GRB revealed that significantly positive $500 \mathrm{hPa}$ geopotential height anomalies and anticyclonic patterns over the GRB can reduce cloud cover, thereby increasing the amount of incoming radiation and the resulting evapotranspiration. Soil moisture deficits reduce evapotranspiration (i.e., high evaporative capacity with low evapotranspiration due to limited water), and a larger proportion of the incoming radiation is employed to warm up the environment, which leads to an accumulation of sensible heat in the surface atmosphere that can develop into a heatwave or exaggerate a heatwave's magnitude [14]. A very dry antecedent surface condition driven by chronic precipitation deficits can create a positive feedback loop between atmospheric heating and further drying of the soil $[3,36,63]$, thereby providing conditions conducive to CDHWs. In fact, the D-H dependence reflects the characteristics of the coupling between the land and the atmosphere [3]. In general, the soil moisture deficit is influenced by enhanced land-atmosphere coupling during summer, which appears to intensify surface warming and anticyclonic circulation anomalies, eventually leading to CDHWs [64]. ERA5 could better capture the spatial characteristics of the D-H dependence in the GRB, and a relatively stronger D-H dependence in the southern parts of the basin produced a higher probability of CDHWs. Previous studies also demonstrated that a high risk of CDHWs existed in southern China $[3,65]$. On the basis that ERA5 can better reflect the characteristics of the CDHMI cumulative probability density in the GRB, we found that higher the CDHMI value, the greater the severity of drought and the duration of heatwaves. 
The total population of the GRB increased significantly from 1988 to 2018. An increase in population can increase the risk of more population being exposed to CDHWs. ERA5 better reflected the annual variations of the exposure values for CDHW frequency and CDHMI, with $r$-values above 0.8 and $R B$ values within $15 \%$. Regardless of the grades (magnitude) of CDHWs, the increasing trend of the ERA5-simulated exposure of CDHW frequency was more apparent than the observed frequency, which was related to the annual frequency variations of CDHWs in the ERA5 and observations. CDHWs also presented an upward trend on the global scale [54]. The moderate CDHW frequency exposure showed a significant upward trend both in the observations and in ERA5. However, the population exposure to severe, extreme, and exceptional CDHWs did not show clear upward trends. As the CDHMI increased, the characteristics of the multi-annual variability also became more apparent.

From $T_{1}$ to $T_{3}$, the population exposure to CDHWs basically increased in the observations and ERA5. This increase was particularly high for moderate CDHWs due to increased population and hot extremes. The contributions of the climate change effect to CDHW exposures were much greater than those of population and joint change effects. This was different from the results of exposure characteristics related to extreme climate events reported in previous studies $[41,42,44]$, because the previous studies were based on future climate and population outputs by the models. Under the characteristics of different CDHW grades, the contribution rates of climate change effect were basically the main cause for the change in the CDHW exposures. In $\mathrm{T}_{3-1}$, with the increased in the CDHMI, the contributions of population change effects had gradually increased, especially under the exceptional CDHW exposures.

According to the results of this study, the population exposed to CDHWs has increased in the GRB (Figure 17). A comprehensive understanding of the mechanisms of CDHWs plays a vital role in predicting CDHWs and thus providing adaptive responses for different populations. The spatio-temporal characteristics of CDHWs were associated with local and teleconnected land-atmosphere feedbacks [14,66], which may promote the intensification and propagation (expansion and concatenation) of CDHWs. Elucidating the relative contributions from local (i.e., self-intensification) and teleconnected (i.e., selfpropagation, such as the inflow of heat to other regions) land-atmosphere feedbacks in a more comprehensive manner can advance our understanding of CDHW mechanisms, and will be conducted in future work. Extreme heatwaves such as the 2010 Russian heatwave can be intensified by the weakened soil moisture constraints [10]. Will the future equivalent of the 2003 CDHW in the GRB increase in its severity due to the weakening soil moisture constraints? This question will be investigated in future work based on the sixth phase of the Coupled Model Intercomparison Project (CMIP6). Different age-related physiological and thermoregulatory properties allow the body to adapt to CDHWs. People $\leq 14$ and $\geq 65$ years of age (i.e., younger and older individuals) are more vulnerable to hot extremes and experience greater heat-related health impacts than others [67-70]. Future work will explore the exposure of children and elderly people to CDHWs and investigate the extent to which different groups or occupations are affected by CDHWs. 


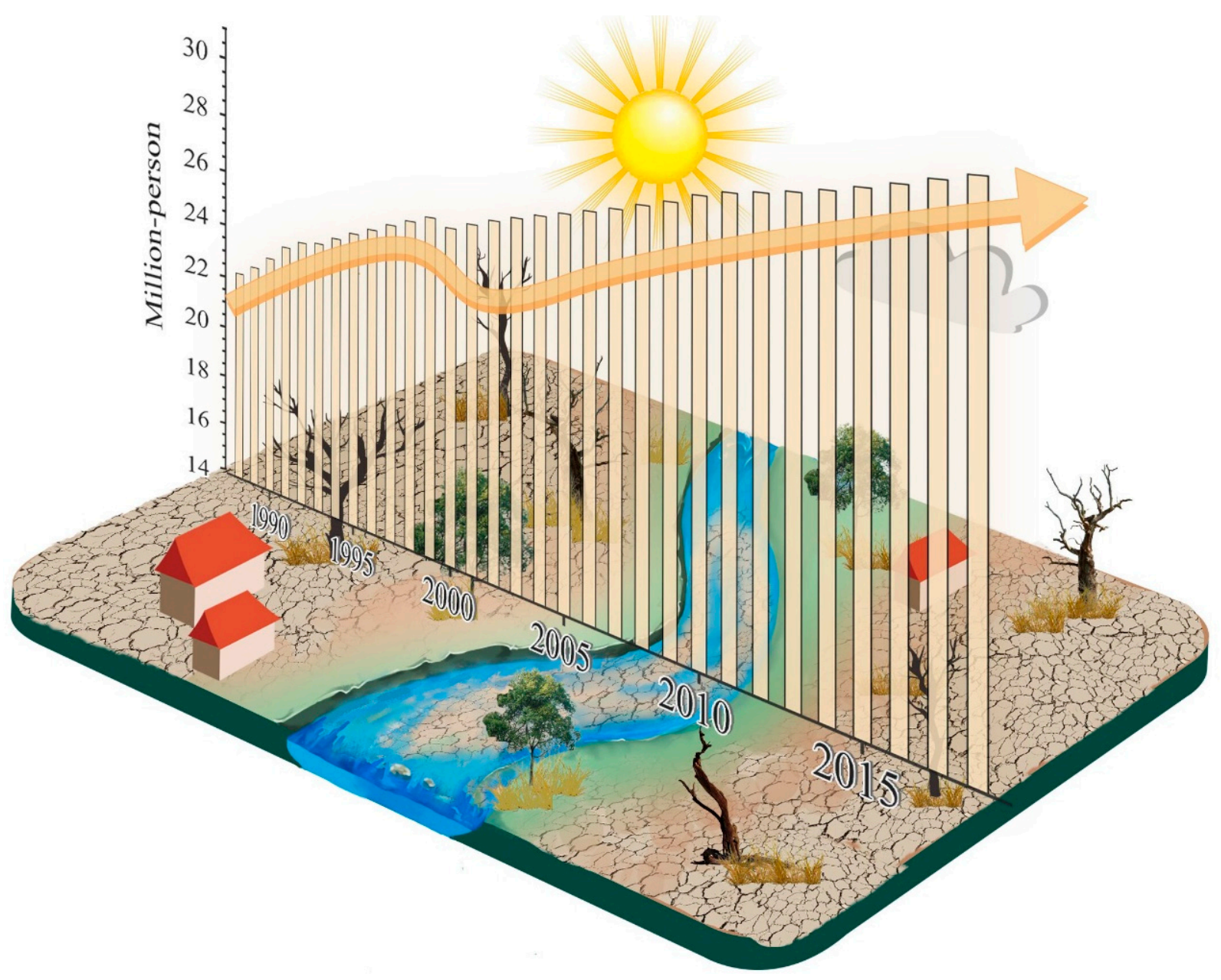

Figure 17. Schematic diagram of population exposure to compound droughts and heatwaves over the GRB.

\section{Conclusions}

CDHWs are more harmful to human health than individual extremes, especially in areas with high population density. This study used the GRB as a case to explore CDHW characteristics and quantify the population exposed to them both in the observations and in ERA5. Our conclusions can be summarized as follows:

(1) ERA5 has high simulation accuracy for the temperature, precipitation, one-month SPEI, heatwaves, and CDHWs in the GRB from 1961 to 2018. The CDHWs during 1997-2018 were slightly higher than during 1961-1997, especially due to significant increases in heatwaves from 1997 to 2018. Relatively high values of D-H dependence indices existed in the southern parts of the basin, indicating that CDHWs were more likely to occur in this region.

(2) The large CDHMI values were attributed to the enhanced interaction between droughts and heatwaves during the specific periods. According to the case of the 2003 summer CDHW in the GRB, strongly positive $500 \mathrm{hPa}$ geopotential height, anticyclonic circulation (positive values of water vapor flux divergence anomalies), convective inhibition, and surface net solar radiation anomalies over the GRB could have easily caused CDHWs.

(3) The population of the GRB increased significantly from 1988 to 2018, which increased the risks of CDHW exposure, especially for moderate CDHWs. Population exposure to CDHWs basically increased from $\mathrm{T}_{1}$ to $\mathrm{T}_{3}$, especially in ERA5. The contributions of the climate change effect to CDHW exposure were much greater than the contributions of the population and joint change effects. The contributions of population change effects gradually increased with increasing CDHMI during $\mathrm{T}_{3-1}$ in the observations and ERA5. 
Author Contributions: Conceptualization, Y.Z. and G.M.; methodology, Y.Z.; software, Y.Z. and L.S.; formal analysis, Y.Z. and C.C.; data curation, Y.Z. and L.S.; writing-original draft preparation, Y.Z.; writing-review and editing, Y.Z. and C.C.; visualization, Y.Z. and B.X.; supervision, C.C. and G.M.; funding acquisition, Y.Z. and G.M. All authors have read and agreed to the published version of the manuscript.

Funding: This study was jointly supported by the Humanities and Social Sciences Foundation of the Chinese Ministry of Education (19YJCZH259; 18YJA790061), the National Natural Science Foundation of China (41907384), the Social Science Foundation of Jiangsu Province (18EYB008), and the Huaishang Talent Foundation (42ZYQ00).

Institutional Review Board Statement: Not applicable.

Informed Consent Statement: Not applicable.

Data Availability Statement: The data that support our research findings are available from the corresponding author on request.

Acknowledgments: We are very grateful to the anonymous reviewers for their constructive comments and thoughtful suggestions.

Conflicts of Interest: The authors declare no conflict of interest in this study.

\section{References}

1. Zhang, Y.; Sun, X.; Chen, C. Characteristics of concurrent precipitation and wind speed extremes in China. Weather Clim. Extrem. 2021, 32, 100322. [CrossRef]

2. Zscheischler, J.; Martius, O.; Westra, S.; Bevacqua, E.; Raymond, C.; Horton, R.M.; van den Hurk, B.; AghaKouchak, A.; Jézéquel, A.; Mahecha, M.D.; et al. A typology of compound weather and climate events. Nat. Rev. Earth Environ. 2020, 1, $333-347$. [CrossRef]

3. Kong, Q.; Guerreiro, S.B.; Blenkinsop, S.; Li, X.-F.; Fowler, H.J. Increases in summertime concurrent drought and heatwave in Eastern China. Weather Clim. Extrem. 2020, 28, 100242. [CrossRef]

4. Mazdiyasni, O.; Aghakouchak, A. Substantial increase in concurrent droughts and heatwaves in the United States. Proc. Natl. Acad. Sci. USA 2015, 112, 11484-11489. [CrossRef] [PubMed]

5. Raymond, C.; Horton, R.M.; Zscheischler, J.; Martius, O.; AghaKouchak, A.; Balch, J.; Bowen, S.G.; Camargo, S.J.; Hess, J.; Kornhuber, K.; et al. Understanding and managing connected extreme events. Nat. Clim. Chang. 2020, 10, 611-621. [CrossRef]

6. Zhang, Y.; Yang, X.; Chen, C. Substantial decrease in concurrent meteorological droughts and consecutive cold events in Huai River Basin, China. Int. J. Climatol. 2021. preprint. [CrossRef]

7. Ridder, N.; Pitman, A.; Westra, S.; Do, H.; Bador, M.; Hirsch, A.; Evans, J.; Di Luca, A.; Zscheischler, J. Global hotspots for the occurrence of compound events. Nat. Commun. 2020, 11, 5956. [CrossRef] [PubMed]

8. Zscheischler, J.; Westra, S.; Hurk, B.J.; Seneviratne, S.I.; Ward, P.J.; Pitman, A.; AghaKouchak, A.; Bresch, D.N.; Leonard, M.; Wahl T. Future climate risk from compound events. Nat. Clim. Chang. 2018, 8, 469-477. [CrossRef]

9. Ciais, P.; Reichstein, M.; Viovy, N.; Granier, A.; Ogee, J.; Allard, V.; Aubinet, M.; Buchmann, N.; Bernhofer, C.; Carrara, A. Europe-wide reduction in primary productivity caused by the heat and drought in 2003. Nature 2005, 437, 529-533. [CrossRef]

10. Rasmijn, L.; van der Schrier, G.; Bintanja, R.; Barkmeijer, J.; Sterl, A.; Hazeleger, W. Future equivalent of 2010 Russian heatwave intensified by weakening soil moisture constraints. Nat. Clim. Chang. 2018, 8, 381. [CrossRef]

11. Sun, Y.; Zhang, X.; Zwiers, F.W.; Song, L.; Wan, H.; Hu, T.; Yin, H.; Ren, G. Rapid increase in the risk of extreme summer heat in Eastern China. Nat. Clim. Chang. 2014, 4, 1082-1085. [CrossRef]

12. Zscheischler, J.; Fischer, E.M. The record-breaking compound hot and dry 2018 growing season in Germany. Weather Clim. Extrem. 2020, 29, 100270. [CrossRef]

13. IPCC. Managing the Risks of Extreme Events and Disasters to Advance Climate Change Adaptation. Special Report of Working Groups I and II of the Intergovernmental Panel on Climate Change; Cambridge University Press: Cambridge, UK; New York, NY, USA, 2012.

14. Miralles, D.G.; Gentine, P.; Seneviratne, S.I.; Teuling, A.J. Land-atmospheric feedbacks during droughts and heatwaves: State of the science and current challenges. Ann. N. Y. Acad. Sci. 2019, 1436, 19-35. [CrossRef]

15. Hao, Z.; Aghakouchak, A.; Phillips, T.J. Changes in concurrent monthly precipitation and temperature extremes. Environ. Res. Lett. 2013, 8, 034014. [CrossRef]

16. Hao, Z.; Hao, F.; Singh, V.P.; Zhang, X. Changes in the severity of compound drought and hot extremes over global land areas. Environ. Res. Lett. 2018, 13, 124022. [CrossRef]

17. Wu, X.; Hao, Z.; Hao, F.; Zhang, X. Variations of compound precipitation and temperature extremes in China during 1961-2014. Sci. Total Environ. 2019, 663, 731-737. [CrossRef]

18. Aghakouchak, A.; Cheng, L.; Mazdiyasni, O.; Farahmand, A. Global warming and changes in risk of concurrent climate extremes: Insights from the 2014 California drought. Geophys. Res. Lett. 2015, 41, 8847-8852. [CrossRef] 
19. Wu, X.; Hao, Z.; Hao, F.; Singh, V.P.; Zhang, X. Dry-hot magnitude index: A joint indicator for compound event analysis. Environ. Res. Lett. 2019, 064017. [CrossRef]

20. Yu, R.; Zhai, P. More frequent and widespread persistent compound drought and heat event observed in China. Sci Rep. 2020, 10, 14576. [CrossRef] [PubMed]

21. Li, X.; You, Q.; Ren, G.; Wang, S.; Zhang, Y.; Yang, J.; Zhen, G. Concurrent droughts and hot extremes in Northwest China from 1961 to 2017. Int. J. Climatol. 2019, 2186-2196. [CrossRef]

22. Wang, P.; Tang, J.; Sun, X.; Wang, S.; Jian, W.; Dong, X.; Fang, J.; Wang, P.; Tang, J.; Sun, X. Heatwaves in China: Definitions, leading patterns and connections to large-scale atmospheric circulation and SSTs: Heatwaves in China. J. Geophys. Res. Atmos. 2017, 122, 10679-10699. [CrossRef]

23. Russo, S.; Sillmann, J.; Fischer, E.M. Top ten European heatwaves since 1950 and their occurrence in the coming decades. Environ. Res. Lett. 2015, 10, 124003. [CrossRef]

24. Trenberth, K.E.; Dai, A.; van der Schrier, G.; Jones, P.D.; Barichivich, J.; Briffa, K.R.; Sheffield, J. Global warming and changes in drought. Nat. Clim. Chang. 2014, 4, 17-22. [CrossRef]

25. Tian, L.; Leasor, Z.T.; Quiring, S.M. Developing a hybrid drought index: Precipitation Evapotranspiration Difference Condition Index. Risk Manag. 2020, 29, 100238. [CrossRef]

26. Vicente-Serrano, S.M.; Beguería, S.; Lópezmoreno, J.I. A multiscalar drought index sensitive to global warming: The standardized precipitation evapotranspiration index. J. Clim. 2010, 23, 1696-1718. [CrossRef]

27. Taszarek, M.; Kendzierski, S.; Pilguj, N. Hazardous weather affecting European airports: Climatological estimates of situations with limited visibility, thunderstorm, low-level wind shear and snowfall from ERA5. Weather Clim. Extrem. 2020, $28,100243$. [CrossRef]

28. Olauson, J. ERA5: The new champion of wind power modelling? Renew. Energy 2018, 126, 322-331. [CrossRef]

29. Senatore, A.; Davolio, S.; Furnari, L.; Mendicino, G. Reconstructing Flood Events in Mediterranean Coastal Areas Using Different Reanalyses and High-Resolution Meteorological Models. J. Hydrometeorol. 2020, 21, 1865-1887. [CrossRef]

30. Huai, B.; Wang, J.; Sun, W.; Wang, Y.; Zhang, W. Evaluation of the near-surface climate of the recent global atmospheric reanalysis for Qilian Mountains, Qinghai-Tibet Plateau. Atmos. Res. 2021, 250, 105401. [CrossRef]

31. Owen, L.E.; Catto, J.L.; Stephenson, D.B.; Dunstone, N.J. Compound precipitation and wind extremes over Europe and their relationship to extratropical cyclones. Weather Clim. Extrem. 2021, 100342. [CrossRef]

32. Jiang, Q.; Li, W.; Fan, Z.; He, X.; Sun, W.; Chen, S.; Wen, J.; Gao, J.; Wang, J. Evaluation of the ERA5 reanalysis precipitation dataset over Chinese Mainland. J. Hydrol. 2021, 595, 125660. [CrossRef]

33. Li, X.; Huang, W.-R. How long should the pre-existing climatic water balance be considered when capturing short-term wetness and dryness over China by using SPEI? Sci. Total Environ. 2021, 786, 147575. [CrossRef]

34. Fischer, E.M.; Schär, C. Consistent geographical patterns of changes in high-impact European heatwaves. Nat. Geosci. 2010, 3, 398-403. [CrossRef]

35. Bakhsh, K.; Rauf, S.; Zulfiqar, F. Adaptation strategies for minimizing heat wave induced morbidity and its determinants. Sustain. Cities Soc. 2018, 41, 95-103. [CrossRef]

36. Zhang, Y.; Mao, G.; Chen, C.; Lu, Z.; Luo, Z.; Zhou, W. Population exposure to concurrent daytime and nighttime heatwaves in Huai River Basin, China. Sustain. Cities Soc. 2020, 61, 102309. [CrossRef]

37. Malmquist, A.; Lundgren, T.; Hjerpe, M.; Glaas, E.; Turner, E.; Storbjörk, S. Vulnerability and adaptation to heat waves in preschools: Experiences, impacts and responses by unit heads, educators and parents. Clim. Risk Manag. 2021, $31,100271$. [CrossRef]

38. Ding, T.; Ke, Z. Characteristics and changes of regional wet and dry heat wave events in China during 1960-2013. Theor. Appl. Climatol. 2015, 122, 651-665. [CrossRef]

39. Lin, L.; Ge, E.; Liu, X.; Liao, W.; Luo, M. Urbanization effects on heat waves in Fujian Province, Southeast China. Atmos. Res. 2018, 210, 123-132. [CrossRef]

40. Lv, Y.; Li, W.; Wen, J.; Xu, H.; Du, S. Population pattern and exposure under sea level rise: Low elevation coastal zone in the Yangtze River Delta, 1990-2100. Clim. Risk Manag. 2021, 100348. [CrossRef]

41. Liao, X.; Xu, W.; Zhang, J.; Li, Y.; Tian, Y. Global exposure to rainstorms and the contribution rates of climate change and population change. Sci. Total Environ. 2019, 663, 644-653. [CrossRef]

42. Jones, B.; O’Neill, B.C.; Mcdaniel, L.; Mcginnis, S.; Mearns, L.O.; Tebaldi, C. Future population exposure to US heat extremes. Nat. Clim. Chang. 2015, 5, 652-655. [CrossRef]

43. Chen, J.; Liu, Y.; Pan, T.; Liu, Y.; Sun, F.; Ge, Q. Population exposure to droughts in China under the $1.5^{\circ} \mathrm{C}$ global warming target. Earth Syst. Dyn. 2018, 9, 1097-1106. [CrossRef]

44. Wu, X.; Hao, Z.; Tang, Q.; Zhang, X.; Feng, S.; Hao, F. Population exposure to compound dry and hot events in China under 1.5 and $2{ }^{\circ} \mathrm{C}$ global warming. Int. J. Climatol 2021. preprint. [CrossRef]

45. Zhang, Y.; You, Q.; Chen, C.; Xin, L. Flash droughts in a typical humid and subtropical basin: A case study in the Gan River Basin, China. J. Hydrol. 2017, 551, 162-176. [CrossRef]

46. Zhang, Y.; You, Q.; Mao, G.; Chen, C.; Ye, Z. Short-term concurrent drought and heatwave frequency with 1.5 and $2.0^{\circ} \mathrm{C}$ global warming in humid subtropical basins: A case study in the Gan River Basin, China. Clim. Dyn. 2019, 52, 4621-4641. [CrossRef] 
47. Hersbach, H.; Bell, B.; Berrisford, P.; Hirahara, S.; Horányi, A.; Muñoz-Sabater, J.; Nicolas, J.; Peubey, C.; Radu, R.; Schepers, D.; et al. The ERA5 global reanalysis. Q. J. R. Meteorol. Soc. 2020, 146, 1999-2049. [CrossRef]

48. Zhou, Q.; Chen, D.; Hu, Z.; Chen, X. Decompositions of Taylor diagram and DISO performance criteria. Int. J. Climatol. 2021. [CrossRef]

49. Hu, Z.; Chen, X.; Zhou, Q.; Chen, D.; Li, J. DISO: A rethink of Taylor diagram. Int. J. Climatol. 2019, 39, 2825-2832. [CrossRef]

50. Wang, F.; Wang, Z.; Yang, H.; Di, D.; Zhao, Y.; Liang, Q. A new copula-based standardized precipitation evapotranspiration streamflow index for drought monitoring. J. Hydrol. 2020, 585, 124793. [CrossRef]

51. Zhang, Y.; You, Q.; Lin, H.; Chen, C. Analysis of dry/wet conditions in the Gan River Basin, China, and their association with large-scale atmospheric circulation. Glob. Planet. Chang. 2015, 133, 309-317. [CrossRef]

52. Chen, S. Severe Drought with High Temperature in 2003 over the Jiangxi Province, China; China Meteorological Press: Beijing, China, 2005. (In Chinese)

53. Wen, K.; Chen, S. Grand Dictionary of China Meteorological Disasters: Volume Jiangxi; China Meteorological Press: Beijing, China, 2006. (In Chinese)

54. Mukherjee, S.; Mishra, A.K. Increase in Compound Drought and Heatwaves in a Warming World. Geophys. Res. Lett. 2021, 48, e2020GL090617. [CrossRef]

55. Chen, K.; Bi, J.; Chen, J.; Chen, X.; Huang, L.; Zhou, L. Influence of heat wave definitions to the added effect of heat waves on daily mortality in Nanjing, China. Sci. Total Environ. 2015, 506-507, 18-25. [CrossRef] [PubMed]

56. Wu, J.; Zhang, L.; Gao, Y.; Zhao, D.; Zha, J.; Yang, Q. Impacts of cloud cover on long-term changes in light rain in Eastern China Int. J. Climatol. 2017, 37, 4409-4416. [CrossRef]

57. Zhang, Y.; Liu, C.; You, Q.; Chen, C.; Xie, W.; Ye, Z.; Li, X.; He, Q. Decrease in light precipitation events in Huai River Eco-economic Corridor, a climate transitional zone in eastern China. Atmos. Res. 2019, 226, 240-254. [CrossRef]

58. Li, X.-X. Heat wave trends in Southeast Asia during 1979-2018: The impact of humidity. Sci. Total Environ. 2020, $721,137664$. [CrossRef] [PubMed]

59. Qiao, S.; Chen, D.; Wang, B.; Cheung, H.-N.; Liu, F.; Cheng, J.; Tang, S.; Zhang, Z.; Feng, G.; Dong, W. The Longest 2020 Meiyu Season Over the Past 60 years: Subseasonal Perspective and Its Predictions. Geophys. Res. Lett. 2021, 48, e2021GL093596. [CrossRef]

60. Wang, M.; Gu, Q.; Jia, X.; Ge, J. An assessment of the impact of Pacific Decadal Oscillation on autumn droughts in North China based on the Palmer drought severity index. Int. J. Climatol. 2019, 39, 5338-5350. [CrossRef]

61. Liu, J.; Zhai, P. Changes in Climate Regionalization Indices in China during 1961-2010. Adv. Atmos. Sci. 2014, 31. [CrossRef]

62. Liu, F.; Ouyang, Y.; Wang, B.; Yang, J.; Ling, J.; Hsu, P.-C. Seasonal evolution of the intraseasonal variability of China summer precipitation. Clim. Dyn. 2020, 54, 4641-4655. [CrossRef]

63. Perkins, S.E. A review on the scientific understanding of heatwaves-Their measurement, driving mechanisms, and changes at the global scale. Atmos. Res. 2015, 164-165, 242-267. [CrossRef]

64. Zhang, P.; Jeong, J.-H.; Yoon, J.-H.; Kim, H.; Wang, S.Y.S.; Linderholm, H.W.; Fang, K.; Wu, X.; Chen, D. Abrupt shift to hotter and drier climate over inner East Asia beyond the tipping point. Science 2020, 370, 1095-1099. [CrossRef] [PubMed]

65. Zhang, H.; Wu, C.; Hu, B.X. Recent intensification of short-term concurrent hot and dry extremes over the Pearl River Basin, china. Int. J. Climatol. 2019, 39, 4924-4937. [CrossRef]

66. Hao, Z.; Hao, F.; Singh, V.P.; Zhang, X. Quantifying the relationship between compound dry and hot events and El Niño-Southern Oscillation (ENSO) at the global scale. J. Hydrol. 2018, 567, 332-338. [CrossRef]

67. Wang, Y.; Wang, A.; Zhai, J.; Tao, H.; Jiang, T.; Su, B.; Yang, J.; Wang, G.; Liu, Q.; Gao, C. Tens of thousands additional deaths annually in cities of china between $1.5^{\circ} \mathrm{C}$ and $2.0^{\circ} \mathrm{C}$ warming. Nat. Commun. 2019, 10, 3376. [CrossRef]

68. Chae, Y.; Park, J. Analysis on Effectiveness of Impact Based Heatwave Warning Considering Severity and Likelihood of Health Impacts in Seoul, Korea. Int. J. Environ. Res. Public Health 2021, 18, 2380. [CrossRef]

69. Park, J.; Chae, Y.; Choi, S.H. Analysis of Mortality Change Rate from Temperature in Summer by Age, Occupation, Household Type, and Chronic Diseases in 229 Korean Municipalities from 2007-2016. Int. J. Environ. Res. Public Health 2019, $16,1561$. [CrossRef] [PubMed]

70. Pamla, A.; Thondhlana, G.; Ruwanza, S. Persistent Droughts and Water Scarcity: Households' Perceptions and Practices in Makhanda, South Africa. Land 2021, 10, 593. [CrossRef] 